\title{
70 años de los estudios latinoamericanos en China: una perspectiva del desarrollo institucional
}

Latin American studies in China (1949-2019): an institutional development perspective

Guo Cunhai ${ }^{\mathbb{1}}$

\section{Resumen:}

Desde la fundación de la República Popular de China en 1949 hasta hoy, la materia de los estudios latinoamericanos en China ha pasado de la nada a ser algo, del estancamiento a la recuperación y hasta el modelo de desarrollo "explosivo" actual. Con el fin de conocer en detalle la situación actual del desarrollo de los estudios latinoamericanos en China y su tendencia futura, el presente ensayo se fundamenta principalmente en la Encuesta sobre el desarrollo de instituciones de estudios latinoamericanos en China (1949-2019) y la base de datos de los últimos 40 años de artículos publicados en la Revista de Estudios Latinoamericanos (Ladingmeizhou Yanjiu).

Desde la perspectiva del desarrollo institucional, se analizan las características y los retos que encaran los últimos setenta años de la investigación sobre Latinoamérica en China. Con el propósito de repensar el estudio académico de Latinoamérica en China, la presente obra tiene también la finalidad de promover el rediseño de los estudios latinoamericanos en China. Dicha investigación ha descubierto que, aunque en las últimas décadas, el estudio de Latinoamérica en China ha obtenido progresos significativos en el ámbito de la infraestructura de software y hardware, la excesiva "orientación política" ha restringido la actividad de la investigación académica, ha limitado la efectividad del estudio de políticas,

(1) Doctor en política internacional, vicesecretario general de la Asociación China de Estudios Latinoamericanos, director de Departamento de Estudios Sociales y Culturales de Instituto de América Latina de Academia China de Ciencias Sociales, cofundador y director de la Comunidad de Estudios Chinos y Latinoamericanos (CECLA). Contacto: marsopaguo@gmail.com 
llegando incluso al punto de que la creación de conocimientos sobre Latinoamérica no esté adaptada a las necesidades de la sociedad. Esta clase de distanciamiento demuestra que, por una parte, la creación de conocimientos sobre Latinoamérica es insuficiente en términos cuantitativos y, por otra parte, debido a la reiteración de contenidos, existe un exceso relativo.

Así, la perspectiva, la metodología y el contenido de la investigación de América Latina en China debe enfrentarse a los retos de transformarse. Según la opinión del presente autor, en este nuevo periodo histórico, las instituciones de China dedicadas al estudio de Latinoamérica y los investigadores deben transformar urgentemente su concepción. A través de una perspectiva más amplia, una metodología más académica y una mayor variedad de sujetos de estudio, se mejoraría sustancialmente la investigación, se planificaría una formación académica más "robusta" (hou ji) y se daría un uso a la investigación "capilar" (bo fa) de las políticas.

Palabras clave: China, estudios latinoamericanos, desarrollo institucional, retos transformacionales.

\begin{abstract}
:
Since the founding of the People's Republic of China in 1949, Latin American Studies in China have experienced a development from scratch, from stagnation to recovery, and even to the current "explosion". In order to fully and deeply grasp the current development and its future trend of Latin American Studies in China, this paper, from the perspective of institutional development and based on the first "Survey on the Development of Institutions of Latin American Studies in China" and the 40-year academic database of Journal of Latin American Studies, aims to analyze the development characteristics and transformation challenges confronting China's Latin American Studies, to reflect on China's current Latin American Studies and promote its reconstruction into the future.
\end{abstract}

Orientando. Temas de Asia Oriental. Sociedad, Cultura y Economía. Revista editada por el Centro de Estudios China-Veracruz de la Universidad Veracruzana, México (Centro de Estudios APEC) / año 10 / número 19/ 
Over the past 70 years, Latin American Studies in China have made great progress in academic infrastructure building, while "policy-oriented" research has inhibited the vitality of academic research and restricted its effects on policy making. As a result, the offerings of Latin American Studies have always failed to meet China's demand for knowing better Latin America. This gap reflects the absolute shortage of knowledge on Latin America and the relative surplus due to less-effective research. Consequentially, China's Latin American Studies are confronting the challenges of transformation in terms of research vision, methodologies and contents.

In the new era, China's institutions and scholars of Latin American Studies are in dire need of modernizing their ideas and strengthening academic research with a broader worldwide vision, more scientific methodologies and more diversified contents, both for the purpose of enriching academic accomplishment and delivering well-grounded policy wisdom.

Key Words: China , Latin American Studies, Institutional Development, Transformational Challenges

Orientando. Temas de Asia Oriental. Sociedad, Cultura y Economía. Revista editada por el Centro de Estudios China-Veracruz de la Universidad Veracruzana, México (Centro de Estudios APEC) / año 10 / número 19/ 


\section{Introducción}

Pese a que América Latina y el Caribe ( denominados de aquí en adelante como "Latinoamérica" ), sean la región más distante de China, los estudios latinoamericanos son un importante componente dentro del estudio de la región. Su inicio no ha sido tardío, pues ha sido una región estudiada incluso desde que China comenzó a desarrollarse. Desde la fundación de la República Popular de China en 1949 hasta hoy, los estudios latinoamericanos en China han experimentado profundos cambios, pasando de un "desarrollo fragmentado" a un desarrollo veloz. Para conocer en profundidad e íntegramente el desarrollo institucional con relación a los estudios latinoamericanos en la China contemporánea, el autor ha recibido el encargo de la Asociación China de Estudios Latinoamericanos (Zhongguo Ladingmeizhou Xuehui) para la dirigir, organizar, diseñar e implementar la Encuesta sobre el desarrollo de instituciones de estudios latinoamericanos en China (1949-2019).

Al mismo tiempo, para descubrir los logros actuales en los estudios latinoamericanos en China, el autor también ha organizado las estadísticas de todas las publicaciones académicas, una a una, de la única revista académica sobre Latinoamérica, la Revista de Estudios Latinoamericanos (Ladingmeizhou Yanjiu), que se ha publicado desde 1979 hasta hoy. Esto ayuda al análisis especialmente de las características del desarrollo de los últimos cuarenta años de estudios latinoamericanos en China. El análisis del presente ensayo se basa en la investigación a través de encuestas y la organización de las estadísticas de ensayos académicos de dicha revista académica.

Orientando. Temas de Asia Oriental. Sociedad, Cultura y Economía. Revista editada por el Centro de Estudios China-Veracruz de la Universidad Veracruzana, México (Centro de Estudios APEC) / año 10 / número 19/ 


\section{La motivación y la metodología de la Encuesta sobre el desarrollo de instituciones de estudios latinoamericanos en China ( 1949-2019)}

Los años 1949, 1979 y 2019 no solo son importantes para China, sino que también han sido igual de importantes para el desarrollo de los estudios latinoamericanos en China. En primer lugar, los estudios latinoamericanos en China empezaron a desarrollarse gradualmente tras la fundación de la Nueva China. Por ello, el año 1949 debería concebirse como un punto de partida más adecuado. ${ }^{(1)}$ Analizando estos 70 años, desde la constitución de la Nueva China, a través de una retrospectiva, resumen y reflexión sistemática sobre estos setenta años de desarrollo de los estudios latinoamericanos en China, "volver a reactivar la voluntad y volver a empezar", resulta extremadamente conveniente e importante para los estudios latinoamericanos en China.

En segundo lugar, el concepto de "cambiar lo antiguo por una nueva cara" en los estudios latinoamericanos en China ha seguido estrechamente los pasos de la reforma y apertura de China. Por tanto, 1979 debería ser el comienzo de la transformación científica, académica y sistemática de los estudios latinoamericanos en China.

"La enseñanza sobre Latinoamérica y los estudios latinoamericanos en China inicialmente comenzó centrándose en las cuestiones históricas. (2)” , pero ha sido igual que las traducciones de la literatura precursora sobre los estudios latinoamericanos, que se caracterizaba principalmente por su tono antiimperialista anti-feudal y anticolonialista. "Los estudios sobre la historia de Latinoamérica...los ensayos estaban demasiado ceñidos a su época, por lo que la investigación científica no era suficiente, muchos de los resultados

(1) Wang Xiaode, Lei Yongren. (2000). Retrospectiva de los estudios latinoamericanos en China (《中国拉 丁美洲史研究回顾》, publicado en Investigación de la historia (《历史研究》), volumen 5, p. 150.

(2) Guo Jie. (2016). Los estudios latinoamericanos en China bajo una perspectiva comparativa (《比较视野 下的中国拉美研究》) en Investigación de la política internacional (《国际政治研究》), volumen 5.pp. 86108 .

Orientando. Temas de Asia Oriental. Sociedad, Cultura y Economía. Revista editada por el Centro de Estudios China-Veracruz de la Universidad Veracruzana, México (Centro de Estudios APEC) / año 10 / número 19/ 
académicos eran demasiado exagerados y sensacionalistas ( gao qiang da diao), y carecían de objetividad". (1) Por tanto, muchos de ellos difícilmente se podrían considerar como parte de una investigación académica.

Además, otro tema principal de la investigación académica era el estudio de los problemas reales de Latinoamérica. "En términos generales se ha otorgado demasiada importancia a presentar la situación general de los países latinoamericanos y los conocimientos básicos sobre su situación política y económica... los trabajos de investigación interdisciplinar han sido poco sólidos, y se han dedicado principalmente al análisis de los acontecimientos actuales o comentarios sobre política. Se ha empleado mucho tiempo y esfuerzos en recabar datos y en la traducir documentos extranjeros, en la colección y el procesamiento de los datos". (2)

Posteriormente, debido a la Revolución cultural, hubo una década de disolución de las instituciones dedicadas a los estudios latinoamericanos y al envío de los investigadores y académicos a zonas rurales. Así, los estudios latinoamericanos que acababan de brotar habían sido interrumpidos en esta etapa germinal, y, por tanto, se discontinuaron. Por tanto, esencialmente, en este periodo no hubo un auténtico estudio académico, sino que fundamentalmente se establecieron las condiciones para el estudio científico de los estudios latinoamericanos.

En 1978, la Convención Nacional Científica celebrada con éxito proclamó la llegada de una "primavera científica". La "primavera de los estudios latinoamericanos" también llegaría después. En octubre de 1979 , la Asociación de Estudios de Literatura de China e

\footnotetext{
(1) Wang Xiaode, Lei Yongren. (2000). Retrospectiva de los estudios latinoamericanos en China (《中国拉 丁美洲史研究回顾》, publicado en Investigación de la historia (《历史研究》), volumen 5, p. 153.

(2) Yuan Dongzhen et al.: 70 años de estudios latinoamericanos en China (《中国拉丁美洲研究 70 年》) se publicará en el libro editado por Zhou Hong: 70 años de estudio de cuestiones internacionales (《国际问题 研究 70 年》).
}

Orientando. Temas de Asia Oriental. Sociedad, Cultura y Economía. Revista editada por el Centro de Estudios China-Veracruz de la Universidad Veracruzana, México (Centro de Estudios APEC) / año 10 / número 19/ 
Iberoamérica, ( ahora referida como rama académica sobre la literatura iberoamericana de la asociación académica sobre literatura extranjera ) fue fundada en Nanjing. En noviembre de ese año, la primera publicación académica en China sobre temas de Latinoamérica, Colección de Estudios Latinoamericanos (Ladingmeizhou Congkan) fue publicada oficialmente $^{\circledR}$. En diciembre, se fundó la Asociación China de Estudios de Historia Latinoamericana en Wuhan. Cinco años después, en 1984, una asociación civil sobre estudios latinoamericanos llamada Asociación China de Estudios Latinoamericanos que, hoy en día es la más relevante a nivel nacional, fue fundada. Hasta hoy, bien sea por la creación de plataformas académicas, o bien por el desarrollo sistemático a través de grupos académicos, los estudios latinoamericanos han avanzado sustancialmente y empezado una auténtica historia en China.

Por último, el ascenso de China ha hecho que esta potencia emergente se haya acercado cada vez más a Latinoamérica y que los estudios latinoamericanos en China hayan pasado a una nueva etapa. Así, concibiendo un desarrollo "explosivo". Este tipo de desarrollo "explosivo" implica que la materia ha crecido rápidamente, pero que también ha experimentado un desarrollo desordenado. En esta ocasión, la Revista de Estudios Latinoamericanos está a punto de cumplir cuarenta años, y ha tomado el pulso a los estudios latinoamericanos en China, su situación actual, sus características y sus tendencias, convirtiéndose en una publicación esencial para servir y dirigir el desarrollo sistemático y científico de las instituciones emergentes de los estudios latinoamericanos.

(1) Colección de Estudios Latinoamericanos (《拉丁美洲丛刊》 o Ladingmeizhou congkan) es la única publicación académica dedicada a los estudios latinoamericanos y antecesor de la Revista de Estudios Latinoamericanos (《拉丁美洲研究》o Ladingmeizhou Yanjiu). Comenzó por publicaciones trimestrales y en 1982 paso a publicaciones bimensuales, Chen Shunying, Zhou Junnan: La fundación y el desarrollo de las publicaciones del Instituto de América Latina (《拉美所所刊的创办与发展》), publicado en la obra editada por Liu Guoping: Recuerdos históricos del desarrollo de la filosofía y las ciencias sociales en China - volumen internacional (《中国哲学社会科学发展历程回忆·国际卷》), Editorial China de Ciencias Sociales, 2014, Beijing, p. 184.

Orientando. Temas de Asia Oriental. Sociedad, Cultura y Economía. Revista editada por el Centro de Estudios China-Veracruz de la Universidad Veracruzana, México (Centro de Estudios APEC) / año 10 / número 19/ 
Debido a las razones mencionadas anteriormente, el autor desea firmemente investigar en profundidad y de manera sistemática las actuales instituciones dedicadas a los estudios latinoamericanos en China y su desarrollo. En julio de 2019, el autor dirigió, organizó y ejerció de anfitrión de la Asociación China de Estudios Latinoamericanos para comenzar a realizar la Encuesta sobre el desarrollo de instituciones de estudios latinoamericanos en China (1949-2019). Los estándares han sido fijados por las instituciones de estudios latinoamericanos.

La presente investigación menciona las “instituciones dedicadas a los estudios latinoamericanos", refiriéndose a aquellas instituciones académicas de investigación o de educación superior que se dedican principalmente al estudio académico de la región de Latinoamericana o sus países y que no incluye a los siguientes cuatro tipos de instituciones: ( 1 ) aquellas que se dedican a la investigación de los países BRICS, economías emergentes o regiones y zonas determinadas y mencionan Latinoamérica tangencialmente; ( 2 ) la Universidad de Estudios Extranjeras de Beijing y el Centro de Estudios Mexicanos de la Universidad Nacional Autónoma de México, debido a que dicha institución es una representación de la Universidad Nacional Autónoma de México en China y no una institución académica per se; ( 3 ) las organizaciones civiles dedicadas al estudio de Latinoamérica, como la Comunidad de Estudios Chinos y Latinoamericanos (CECLA), debido a que no financia la investigación, ni ostenta una oficina permanente; o debido a que no tienen una función académica y únicamente son instituciones que funcionan como una plataforma de think tank civil o son subsidiarias de otras instituciones, como el Centro de Estudios Latinoamericanos del Instituto de Charhar; y, ( 4 ) tampoco se incluyen aquellas instituciones creadas con anterioridad y que ya no existen, como por ejemplo, el centro de investigación de Latinoamérica de la Universidad de Fudan, fundado en 1964. Si las instituciones aún existen y operan con un nombre distinto, sus años de antigüedad se 
calculan desde la fecha de su fundación. Por ejemplo, el Centro de Estudios de Historia de Latinoamérica de la Universidad de Nankai, fundado en 1964. Si las instituciones fueron discontinuadas durante su existencia y posteriormente reemergieron con un nombre nuevo, entonces su antigüedad se calculará desde la fecha de reemergencia. Por ejemplo, el Centro de Estudios sobre Brasil de la Universidad de Hubei, fundado en 1978, y que en 2012 cambió su nombre por Centro de Investigación de Brasil (Baxi yanjiu zhongxin).

Así, según los estándares estipulados, la presente investigación ha determinado que hay 56 instituciones dedicadas a los estudios latinoamericanos en China en total. En total se destinaron 56 cuestionarios, de los cuales se recogieron 54, y dentro de los cuales solo 53 fueron válidos y uno fue invalidado. Dichas estadísticas fueron recopiladas en julio de 2019 (1).

El contenido de los cuestionarios de la investigación, en términos generales, han incluido los siguientes tres grandes bloques: la "investigación sobre la situación general de las instituciones" , que principalmente incluye la fecha de fundación, la naturaleza de la institución, la facultad a la que pertenece, etc; la "investigación sobre la situación del personal de investigación", que incluye entre otros aspectos datos sobre el número de investigadores, sus perfiles académicos, la estructura organizativa, los idiomas, las disciplinas académicas, la edad y los campos de investigación, etc; por último, la “investigación sobre los logros conseguidos” , que incluye el número de actividades académicas realizadas, la cantidad de logros académicos conseguidos y las plataformas de promoción de los logros y actividades realizados, entre otros aspectos.

\footnotetext{
(1) Después de esta encuesta, hay otras dos instituciones recientemente establecidas dedicadas a los estudios latinoamericanos, tales como: el Instituto de Intercambio de Pueblo a Pueblo China-Latinoamericano en la Universidad Normal de Jiangsu en la provincia de Jiangsu y el Centro de Estudios del Caribe en la Universidad de Liaocheng en la provincia de Shandong, entre otros.
}

Orientando. Temas de Asia Oriental. Sociedad, Cultura y Economía. Revista editada por el Centro de Estudios China-Veracruz de la Universidad Veracruzana, México (Centro de Estudios APEC) / año 10 / número 19/ 
A continuación, el autor se basa en la Encuesta sobre el desarrollo de instituciones de estudios latinoamericanos en China (1949-2019) y en los 40 años de información disponible de la Revista de Estudios Latinoamericanos (Ladingmeizhou Yanjiu) para analizar el desarrollo de los estudios latinoamericanos en China.

\section{Las características del desarrollo de los estudios latinoamericanos en China}

( 1 ) La orientación política es la característica general en el desarrollo de los estudios latinoamericanos en China

Tras el rápido desarrollo, especialmente de estos últimos 20 años, los estudios latinoamericanos en China han batido récords en cada ámbito, constituyendo nuevas idiosincrasias en su desarrollo reciente. Realmente, la orientación política aún continúa siendo el rasgo general que define el desarrollo de los estudios latinoamericanos en China, presente en cada nivel del desarrollo de este campo académico. Hasta la fecha, su influencia sigue estando igual de presente.

En la década de los años 60 del siglo XX, el estudio de la historia de Latinoamérica tomaba la "revolución" como su temática principal y "la lucha de clases" como guía, lo que conllevó a una falta de calidad académica y objetividad. ${ }^{(1)}$ En 1984, tras la reforma y apertura, Huan Xiang, el director adjunto de la antigua Academia China de Ciencias Sociales en sus palabras de felicitación durante la conferencia donde se fundó la Asociación China de Estudios Latinoamericanos destacó que: "se deben investigar los resultados reales a partir de los problemas de Latinoamérica, para extraer lecciones para las Cuatro Modernizaciones (si hua) de China, y para proveer datos de referencia para la política

(1) Wang Xiaode \& Lei Yongren. (2000). Retrospectiva de los estudios latinoamericanos en China (《中国拉 丁美洲史研究回顾》, publicado en Investigación de la historia (《历史研究》), volumen 5, p. 153.

Orientando. Temas de Asia Oriental. Sociedad, Cultura y Economía. Revista editada por el Centro de Estudios China-Veracruz de la Universidad Veracruzana, México (Centro de Estudios APEC) / año 10 / número 19/ 
exterior y las estrategias sociales y económicas decididas por el gobierno central.”(1) Atendiendo a estas orientaciones, la única revista académica nacional dedicada a los estudios latinoamericanos, que a día de hoy cumple 40 años, Revista de Estudios Latinoamericanos (Ladingmeizhou Yanjiu), siempre se ha mantenido firme en elegir y publicar artículos según las necesidades reales para la creación de la China moderna.” (2)

En la nueva etapa, el Ministerio de Educación ha promovido el desarrollo de los estudios latinoamericanos en la enseñanza superior en Medidas provisionales para la formación y creación de centros de estudios nacionales comparativos y regionales (Guobie he quyu yanjiu jidi peiyu he jianshe zanxing banfa) publicado en 2015, donde el preámbulo estipula que "el fundamento de los estudios nacionales comparativos y regionales tiene como principal objetivo proveer información de consulta para las políticas gubernamentales, y tiene como principal misión, ofrecer información sobre la investigación de políticas.”(3)

Los estudios latinoamericanos, al ser parte del campo de los estudios regionales, han sido impulsados por dicha política. La investigación académica con fines consultivos para la política no es criticable, al fin y al cabo. China no es el único país que posee este enfoque, todo el mundo es igual. Sin embargo, en EE. UU., el país modelo por antonomasia de los estudios latinoamericanos, este tipo de orientación política se abandonó hace tiempo, y, en

(1) Xu Shicheng. (2014). Fundación y desarrollo de la Asociación China de Estudios Latinoamericanos (《中 国拉丁美洲学会的成立和发展》), publicado en el libro editado por Liu Guoping: : 《Recuerdos históricos del desarrollo de la filosofía y las ciencias sociales en China - volumen internacional (《中国哲学社会科学 发展历程回忆·国际卷》). Beijing: Editorial China de Ciencias Sociales, p. 189.

(2) Chen Shunying \& Zhou Junnan. (2014). La fundación y el desarrollo de las publicaciones del Instituto Latinoamericano (《拉美所所刊的创办与发展》), publicado en la obra editada por Liu Guoping: Recuerdos históricos del desarrollo de la filosofía y las ciencias sociales en China - volumen internacional ( 《中国哲 学社会科学发展历程回忆.国际卷》), Editorial China de Ciencias Sociales. Beijing, p. 184.

(3) Publicación oficial por el Ministerio de Educación de China de Medidas provisionales para la formación y creación de centros de estudios nacionales comparativos y regionales （《国别和区域研究基地培育和 建设暂行办法》), Jiao Wai Jian (Supervisión de Asuntos Exteriores Educativos, 教外监) [2015] No. 4,26 de enero de 2015, http://old.moe.gov.cn/publicfiles/business/htmlfiles/moe/s7068/201502/xxgk_183702.html [2019-07-20]

Orientando. Temas de Asia Oriental. Sociedad, Cultura y Economía. Revista editada por el Centro de Estudios China-Veracruz de la Universidad Veracruzana, México (Centro de Estudios APEC) / año 10 / número 19/ 
mayor grado, el estudio académico allí ha pasado a constituir un bien público. Esta orientación se fundamenta en la investigación y es parecida a la creación de conocimientos sin utilidad. Sin embargo, precisamente se trata de "la utilidad de lo no útil" (wuyong zhi yong), lo que ha promovido el enfoque científico en los estudios latinoamericanos allí, y lo que ha retroalimentado la investigación política y mejorado la calidad del estudio de políticas en EE. UU.

En contraste, en China, la orientación política en exclusiva no solo ha limitado en gran medida el rigor académico de los estudios latinoamericanos, sino que también ha dificultado la mejor calidad en investigación de políticas, haciendo difícil destacar la influencia de las políticas. Lo más preocupante es que cada vez parece haber una tendencia más clara: que el estudio de las relaciones entre China y Latinoamérica, guiado por las políticas gubernamentales, está sustituyendo a la investigación académica de Latinoamérica.

En la $28^{\text {a }}$ reunión anual desde su creación, la Asociación China de Estudios Latinoamericanos realizó algunas estadísticas sobre los temas mencionados y se descubrió que en la mayoría de las reuniones los temas a tratar "no son el foco de atención principal” , sino que éste se ubica en otra parte -cuando se conversa sobre Latinoamérica, o bien "se utilizan los recursos como referencia" (yi zi wei jian); o bien la reunión se centra directamente en las relaciones entre China y Latinoamérica como tema principal. (1) Además, las estadísticas también demuestran que desde 1984 hasta 2019, en total hubo nueve reuniones anuales que tuvieron como tema principal las relaciones entre ambas regiones, equivalente a la temática de casi un tercio de las reuniones.

En este nuevo siglo, esta tendencia se ha hecho más patente. Desde 2005 hasta hoy, en las ocho reuniones anuales de estos 15 años, cinco citas trataron sobre las relaciones entre

\footnotetext{
(1) De 1984 a 1999 , la Asociación China de Estudios Latinoamericanos organizaba una anualmente. Posteriormente, cada dos años. Para más detalles puede referirse a http://ilas.cssn.cn/lmxh/nhxshybd/ [201907-18]
}

Orientando. Temas de Asia Oriental. Sociedad, Cultura y Economía. Revista editada por el Centro de Estudios China-Veracruz de la Universidad Veracruzana, México (Centro de Estudios APEC) / año 10 / número 19/ 
ambas regiones, que en los últimos cinco años ha sido una temática reiterada ( 2015, 2017, 2019 ) . Incluso en las conferencias académicas sobre Latinoamérica dedicadas a la historia de esta región, la agenda en sus conferencias anuales gradualmente ha ido cambiando a los movimientos de liberación democrática, la modernización, la globalización e incluso las relaciones entre China y Latinoamérica. (1)

Este tipo de tendencia en los estudios regionales "enfocándose en las relaciones entre China y Latinoamérica" implica una serie de preocupaciones. Primero, en los estudios latinoamericanos en China, muchos se centran en el estudio de esta gran región, pero hay poco análisis en profundad dedicado a los países individualmente. En segundo lugar, en los estudios comparativos entre países hay demasiada investigación enfocada en las relaciones bilaterales entre China y la región, mientras que el estudio desde una perspectiva multidisciplinar de las diferencias entre los países a distintos niveles es escaso. En tercer lugar, con respecto a la metodología de la investigación, los académicos dedicados al análisis de documentos y al "análisis de políticas a puerta cerrada" (bi men si ce) es excesivo, mientras que la investigación in situ y de referencia es muy escasa. En realidad, esto casi resulta ser una trampa difícil de evitar en los estudios latinoamericanos orientados por las políticas. Asimismo, este rasgo fundamental en el desarrollo de los estudios latinoamericanos también aparece en cada etapa y nivel del desarrollo de este campo académico.

( 2 ) El ritmo del desarrollo institucional dedicado a los estudios latinoamericanos sigue el compás de las importantes coyunturas políticas

\footnotetext{
(1) Han Qi. (2017). Estudios latinoamericanos en universidades de China continental y perspectivas de cooperación con universidades de Taiwán (《大陆高校的拉美研究及与台湾高校合作的前景》), publicado en Publicación periódica de la Economía y Comercio de Latinoamérica (《拉丁美洲经贸季刊》)（Taiwán), p. 10.
}

Orientando. Temas de Asia Oriental. Sociedad, Cultura y Economía. Revista editada por el Centro de Estudios China-Veracruz de la Universidad Veracruzana, México (Centro de Estudios APEC) / año 10 / número 19/ 
En estos últimos veinte años, el desarrollo de los estudios latinoamericanos en China ha sido especialmente rápido. Según las encuestas de la investigación de la Asociación China de Estudios Latinoamericanos, desde la creación de la primera institución dedicada al estudio de Latinoamérica en 1961 hasta julio de 2019 , hasta la fecha existes hasta 56 instituciones dedicadas a los estudios latinoamericanos en China (ver Gráfico 1-1 ). De las instituciones fundadas antes del año 2000 que aún existen, solo quedan cuatro instituciones. (1) Más de un $92 \%$ de las instituciones se han creado en este nuevo siglo; y de las 52 instituciones creadas en este siglo, solo 8 fueron creadas en la primera década del siglo XXI. Las instituciones dedicadas a los estudios latinoamericanos fundadas después de 2011 ( incluido ) son 44, y dentro de ellas, más de la mitad (33 instituciones) fueron concebidas en el último lustro ( 2015-2019).

Gráfico 1-1. El rápido desarrollo de las instituciones dedicadas a los estudios latinoamericanos en China ( 1949-2019)

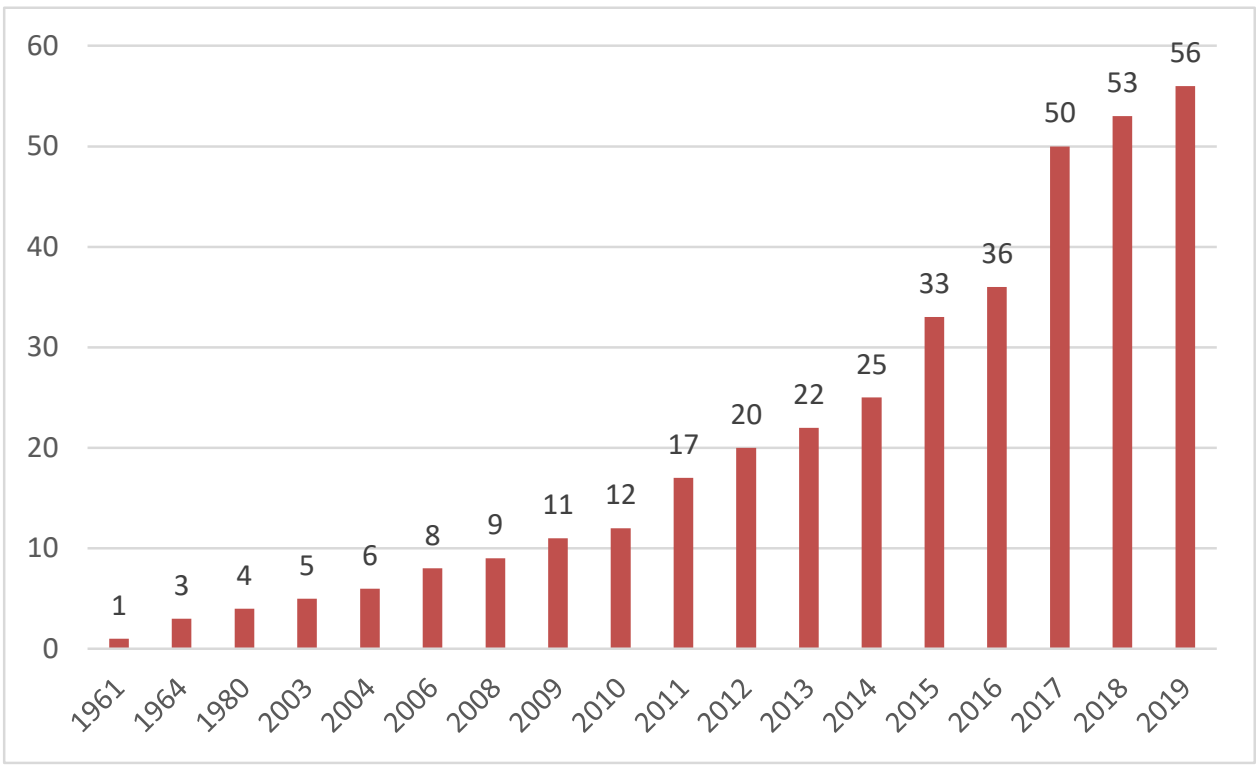

\footnotetext{
${ }^{\oplus}$ Algunos de los primeros institutos dedicados a los estudios latinoamericanos han desaparecido gradualmente debido a la falta de una institución sucesora. Por ejemplo, la Oficina de Estudios Latinoamericanos del Departamento de Historia de la Universidad de Fudan, que se estableció en 1964 (luego asignada a la Oficina de Estudios Latinoamericanos del Instituto de Estudios Internacionales de la Universidad de Fudan) y dejó de existir en 2011.
}

Orientando. Temas de Asia Oriental. Sociedad, Cultura y Economía. Revista editada por el Centro de Estudios China-Veracruz de la Universidad Veracruzana, México (Centro de Estudios APEC) / año 10 / número 19/ 
Fuente : Encuesta sobre el desarrollo de instituciones de estudios latinoamericanos en China (1949-2019) $)^{\circledR}$, Asociación China de Estudios Latinoamericanos, 2019.

La gran mayoría de las nuevas instituciones dedicadas a los estudios latinoamericanos se han establecido en instituciones de enseñanza superior. Esto está estrechamente relacionado con el plan impulsado por el Ministerio de Educación sobre centros de estudios nacionales comparativos y regionales.

En 2011, el vicepresidente Liu Tingdong, en la Reunión de Trabajo sobre la Educación Nacional, puso énfasis en "promover los centros de educación superior en condiciones para fortalecer el estudio de cuestiones relativas a las diferencias nacionales y de regiones". (2)

El Ministerio de Educación posteriormente comenzó a elaborar el plan de estudios nacionales comparativos y de regiones y, en 2012, convocó la primera reunión de trabajo sobre centros de formación para el estudio comparativo entre naciones y regiones. En aquella reunión se anunció la constitución de los primeros 37 centros de formación sobre estudios comparativos nacionales y de regiones. Entre ellos se incluían dos centros dedicados a los estudios latinoamericanos.

En 2015 y 2017, el Ministerio de Educación sucesivamente inició Medidas provisionales para la formación y creación de centros de estudios nacionales comparativos y regionales ${ }^{3}$ y las Pautas sobre la creación de centros de estudios comparativos nacionales

(1) Hay que mencionar que, las estadísticas se han realizado a partir de las 56 instituciones realmente reconocidas, mientras que el número de cuestionarios invalidados refleja la tendencia general del crecimiento de las instituciones de estudios latinoamericanos en China.

(2) Liu Tingdong, "Proseguir la innovación de la revolución, reafirmar la implementación del trabajo, dedicar esfuerzos a crear un nuevo escenario de desarrollo científico en el sector educativo", discurso pronunciado en 2011 en la Asamblea Nacional del Trabajo Educativo, 24 de febrero de 2011, http://www.moe.gov.cn/jyb_xwfb/moe_176/201102/t20110224_115216.html [2019-07-15]

(3) Publicación oficial por el Ministerio de Educación de China de Medidas provisionales para la formación y creación de centros de estudios nacionales comparativos y regionales（《国别和区域研究基地培育和 建设暂行办法》) Jiao Wai Jian (Supervisión de Asuntos Exteriores Educativos，教外监) [2015] No. 4,26 de enero

de 2015 ,

Orientando. Temas de Asia Oriental. Sociedad, Cultura y Economía. Revista editada por el Centro de Estudios China-Veracruz de la Universidad Veracruzana, México (Centro de Estudios APEC) / año 10 / número 19/ 
y regionales (provisionales) (guobie he quyu yanjiu zhongxin jianshe zhiyin ( shixing ) ${ }^{(1)}$, que reforzando la creación de la investigación científica sobre estudios nacionales comparativos y regionales y la formación en asignaturas interdisciplinares emergentes, crearía una gran cantidad de talento humano "experto en estudios comparativos nacionales" y "experto en estudios regionales" para satisfacer la demanda nacional de investigación de importantes políticas. ${ }^{2}$

Con el impulso directo de estos factores, las instituciones dedicadas al estudio de Latinoamérica se desarrollaron extremadamente rápido. Comenzando desde 2011, la aceleración en la creación de instituciones dedicadas a los estudios latinoamericanos ha sido especialmente veloz ( ver Gráfico 1-2 ) , con una media anual de cinco instituciones fundadas por año, especialmente destacan 2015, donde se constituyen ocho instituciones, y 2017, donde se crean otras 14 instituciones. Sin contar con estos dos años excepcionales, en el resto de los años prácticamente se mantuvo una media de tres instituciones creadas por año.

\section{Gráfico 1-2. Incremento anual de las instituciones dedicadas a los estudios latinoamericanos en China}

\footnotetext{
http://old.moe.gov.cn/publicfiles/business/htmlfiles/moe/s7068/201502/xxgk_183702.html[2019-07-20]

(1) Notificación de buena realización de labores para los estudios nacionales comparativos y regionales en 2017 publicado por la Oficina del Ministerio de Educación, Jiao Wai Ting Han (Correspondencia de la Oficina de Exterior de Educación, 教 外 厅 函 ) (2017), No. 8, 23 de febrero de 2017, http://www.moe.gov.cn/srcsite/A20/s7068/201703/t20170314_299521.html[2019-07-28]

(2) Ibíd.
}

Orientando. Temas de Asia Oriental. Sociedad, Cultura y Economía. Revista editada por el Centro de Estudios China-Veracruz de la Universidad Veracruzana, México (Centro de Estudios APEC) / año 10 / número 19/ 


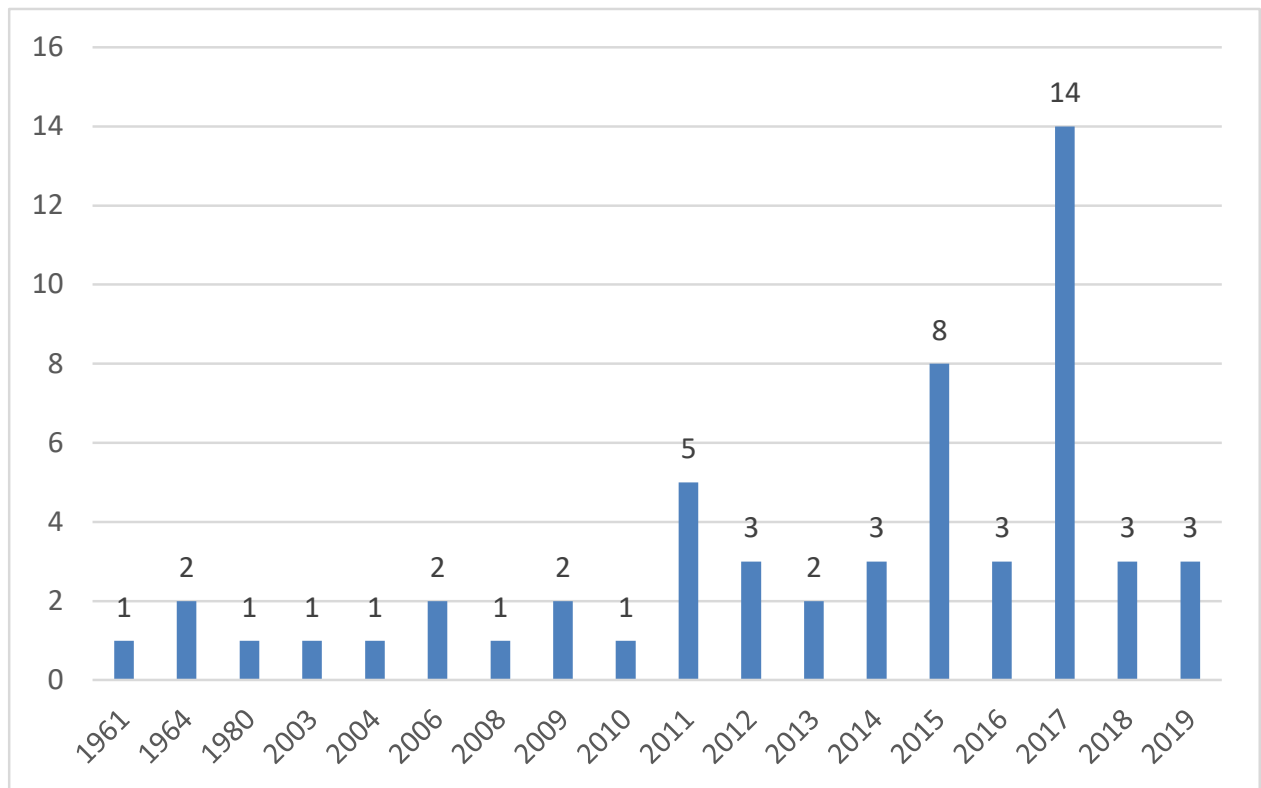

Fuente: Encuesta sobre el desarrollo de instituciones de estudios latinoamericanos en China (1949-2019) $)^{\circledR}$, Asociación China de Estudios Latinoamericanos, 2019.

La proposición e implementación de la iniciativa de la "Franja y la Ruta de la Seda" (yi dai yi lu) se ha convertido en un acelerador para el desarrollo institucional de los estudios latinoamericanos. En 2013, el gobierno de China propuso la iniciativa de la "Franja y la Ruta de la Seda" y, en 2015, publicó oficialmente la Visión y acción para impulsar la construcción conjunta de la franja económica de la Ruta de la Seda y la Ruta de la Seda marítima del siglo XXI (tuidong gongjian sichouzhilu jingji dai he ershiyi shiji haishang sichouzhilu de yuanjing yu xingdong). Latinoamérica no solo es una extensión natural de la "Ruta de la Seda del siglo XXI", sino que también es un importante participante indispensable de la "Franja y la Ruta de la Seda". (2) Este tipo de declaración confirmó oficialmente la relación de Latinoamérica con la "Franja y la Ruta de la Seda".

\footnotetext{
(1) Es necesario mencionar que, las estadísticas se han realizado a partir de las 56 instituciones realmente reconocidas, mientras que el número de cuestionarios invalidados refleja la tendencia general del crecimiento de las instituciones de estudios latinoamericanos en China.

(2) Guo Cunhai et al. (20108). La Franja y la Ruta y América Latina: Nuevas oportunidades y nuevos desafíos (《“一带一路”和拉丁美洲：新机遇与新挑战》). Beijing: Editorial Blossom, VI.
}

Orientando. Temas de Asia Oriental. Sociedad, Cultura y Economía. Revista editada por el Centro de Estudios China-Veracruz de la Universidad Veracruzana, México (Centro de Estudios APEC) / año 10 / número 19/ 
Un año y medio después de esta declaración, 19 países latinoamericanos firmaron el Acuerdo de construcción conjunta de la "Franja y la Ruta de la Seda" con China, representando cerca del $60 \%$ de los países de Latinoamérica. ${ }^{(1)}$ Para el avance de la iniciativa de la "Franja y la Ruta de la Seda" es indispensable el conocimiento de los otros países que conjuntamente construirán el proyecto. Esto hizo más urgente la necesidad de incluir los estudios latinoamericanos en los estudios regionales, lo que aportó una coyuntura nunca presente hasta la fecha para el desarrollo de los estudios de esta región.

La distribución geográfica de las instituciones dedicadas a los estudios latinoamericanos también refleja unas características relacionadas con el desarrollo de políticas y económico. En el Gráfico 1-3 se observa que actualmente, estas instituciones ya están presentes en 18 ciudades de China. ${ }^{2}$

De ellas, solo en Beijing hay hasta 22 instituciones; Shanghái se encuentra en segundo lugar albergando a siete instituciones. Es decir, Beijing y Shanghái concentran más de la mitad de las instituciones a nivel nacional. Esta distribución geográfica está relacionada con las ventajas geográficas, políticas y económicas con las que cuentan ambas ciudades, así como su estatus de metrópolis internacionales y por su concentración de centros de enseñanza superior de calidad. Por detrás pero no muy distantes de Beijing y Shanghái se encuentran las provincias de Jiangsu, Guangdong y Hebei. Una razón para ello es que las relaciones económicas son más estrechas entre Jiangsu y Guangdong con Latinoamérica y, por tanto, precisan de conocimientos relevantes y apoyo inteligente en sus políticas. En el caso de Hebei, se debe a que la relación con Beijing es muy estrecha, debido a la zona de cooperación entre Beijing-Tianjin-Hebei. En realidad, en casi todas las zonas que

(1) Guo Cunhai: 'Comunicaciones de pueblo a pueblo' promueve la construcción conjunta entre China y Latinoamérica de “la Franja y la Ruta” para saltar al nuevo mundo (《“民心相通”推动中拉共建“一带一 路'跃入新境界》), página web Guangming -Videos en el canal de teorías , 25 de abril de 2019, http://theory.gmw.cn/2019-04/25/content 32778646.htm [2019-06-26]

(2) Las estadísticas no incluyen ni a Taiwán, ni las dos Regiones Administrativas Especiales de Hong Kong y Macao.

Orientando. Temas de Asia Oriental. Sociedad, Cultura y Economía. Revista editada por el Centro de Estudios China-Veracruz de la Universidad Veracruzana, México (Centro de Estudios APEC) / año 10 / número 19/ 
mantienen una estrecha cooperación con Latinoamérica existe una institución dedicada a los estudios latinoamericanos, con el fin de satisfacer las necesidades de desarrollo locales en su cooperación con Latinoamérica.

\section{Gráfico 1-3. Cifras y distribución geográfica de las instituciones chinas dedicadas a los estudios latinoamericanos}

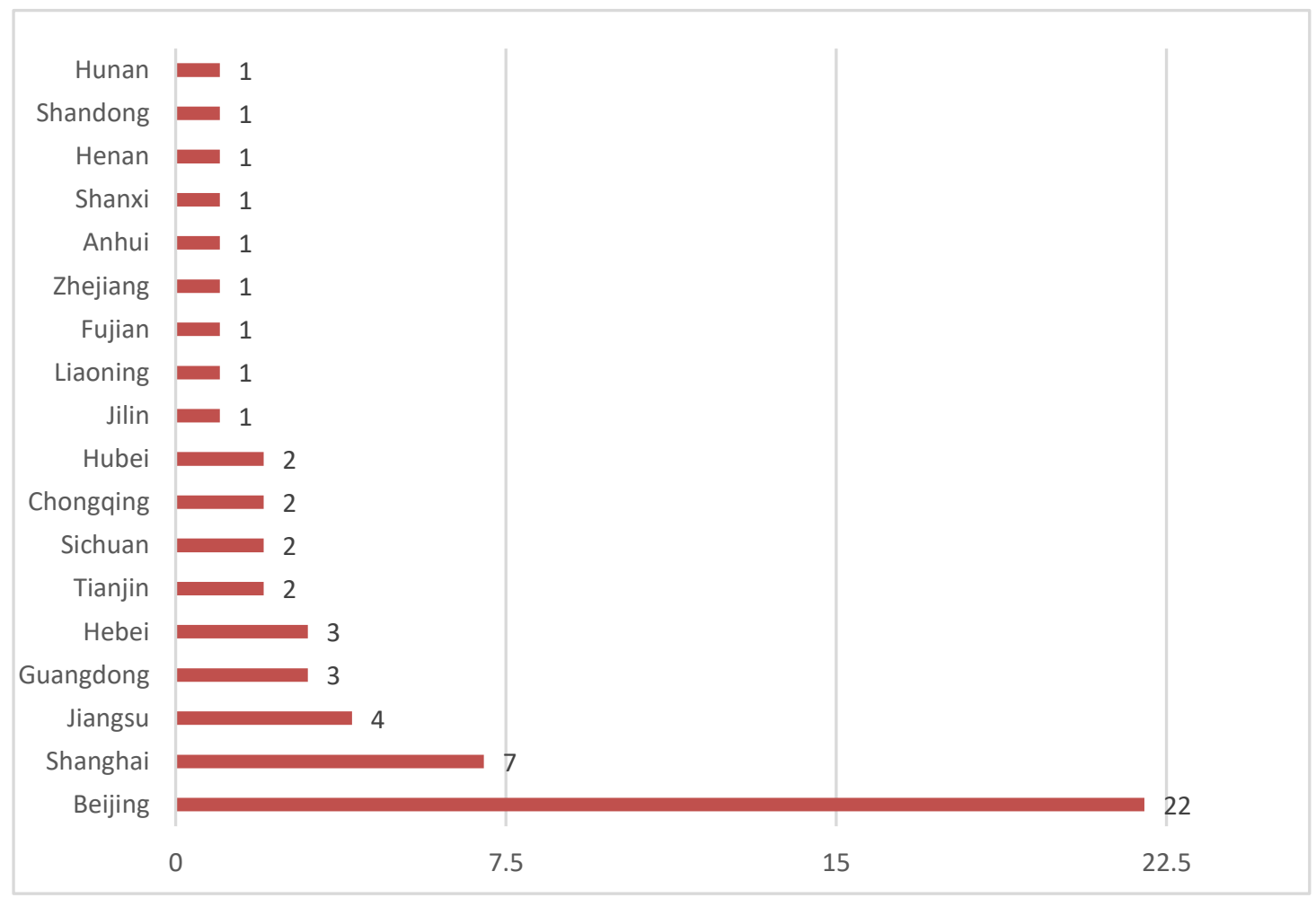

Fuente: Encuesta sobre el desarrollo de instituciones de estudios latinoamericanos en China

(1949-2019) ${ }^{\circledR}$, Asociación China de Estudios Latinoamericanos, 2019.

( 3 ) La naturaleza "vacía de muchas y real de pocas" instituciones ha limitado el potencial de desarrollo de los estudios latinoamericanos

(1) Es necesario mencionar que, las estadísticas se han realizado a partir de las 56 instituciones realmente reconocidas, mientras que el número de cuestionarios invalidados refleja la tendencia general del crecimiento de las instituciones de estudios latinoamericanos en China.

Orientando. Temas de Asia Oriental. Sociedad, Cultura y Economía. Revista editada por el Centro de Estudios China-Veracruz de la Universidad Veracruzana, México (Centro de Estudios APEC) / año 10 / número 19/ 
A pesar de que en los últimos 15 años las instituciones dedicadas al estudio de Latinoamérica han aumentado en un 833\%, alcanzando 56 instituciones, un análisis en detalle de tales instituciones ha descubierto que la naturaleza "vacía de muchas y real de pocas" es una característica general. Que el número de instituciones sea abundante no significa la investigación académica sea fructífera. La naturaleza y el grado de las instituciones, en gran parte, viene determinado por la asignación de recursos que reciben, que influye el potencial de desarrollo de los estudios latinoamericanos. Un estudio en profundidad de las 56 instituciones nacionales ha demostrado que tan solo 17, es decir, un 30\% del total tienen presencia física (shiti) ( ver Gráfico 1- 4 ). Esto indica que, al menos en los aspectos de personal, recursos y materiales, etc, tales elementos físicos, alcanzan una asignación de recursos con garantías, por lo que estas instituciones ofrecen una infraestructura y entorno básicos relativamente mejor para el desarrollo de las labores de investigación.

En comparación, las restantes 39 instituciones no tienen presencia física y constituyen el $70 \%$ del total. Estas segundas encaran dificultades a la hora de conseguir las garantías fundamentales para su infraestructura. Indudablemente, esto influye en la actividad y efectividad de tales instituciones.

Orientando. Temas de Asia Oriental. Sociedad, Cultura y Economía. Revista editada por el Centro de Estudios China-Veracruz de la Universidad Veracruzana, México (Centro de Estudios APEC) / año 10 / número 19/ 
Gráfico 1-4. Comparativa de cifras de las instituciones según su naturaleza física o no física

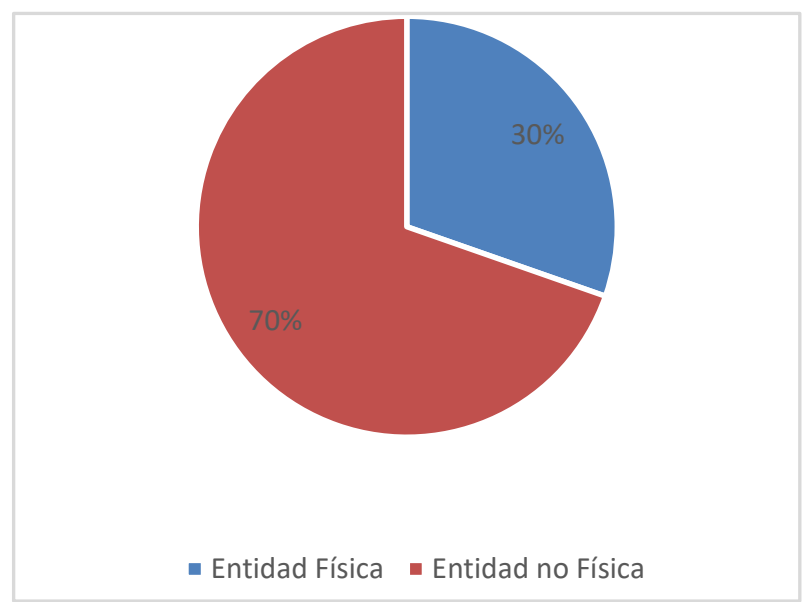

Fuente: Encuesta sobre el desarrollo de instituciones de estudios latinoamericanos en China (1949-2019), Asociación China de Estudios Latinoamericanos, 2019.

Se podría decir que las universidades son la principal fuerza motriz de los estudios latinoamericanos en China. También son la fuente de mayor concentración del aumento de instituciones de estudios latinoamericanos. Dentro de las 56 instituciones dedicadas a estos estudios, hay 50 que pertenecen a universidades y centros de educación superior, casi el 90\%. Por tanto, es necesario realizar un análisis especial sobre tales instituciones en las universidades y centros de educación superior.

En primer lugar, teniendo en cuenta la selección de los centros de estudios nacionales comparativos y regionales del Ministerio de Educación ( ver Gráfico 1-5 ) , tan solo 2 centros ( un 4\% ) de las instituciones de enseñanza superior con estudios latinoamericanos fue seleccionado entre los primeros centros de estudios nacionales comparativos y regionales para entrar en la lista del Ministerio de Educación en 2011. Los otros 19 centros ( un 38\% ), en 2017 entraron en bloque a la lista de centros archivados; al mismo tiempo, 
28 centros (casi un 60\%) no se han clasificado como centros de formación, ni como centros admitidos a trámite.

\section{Gráfico 1-5: Número de centros admitidos por el Ministerio de Educación como instituciones de estudios latinoamericanos}

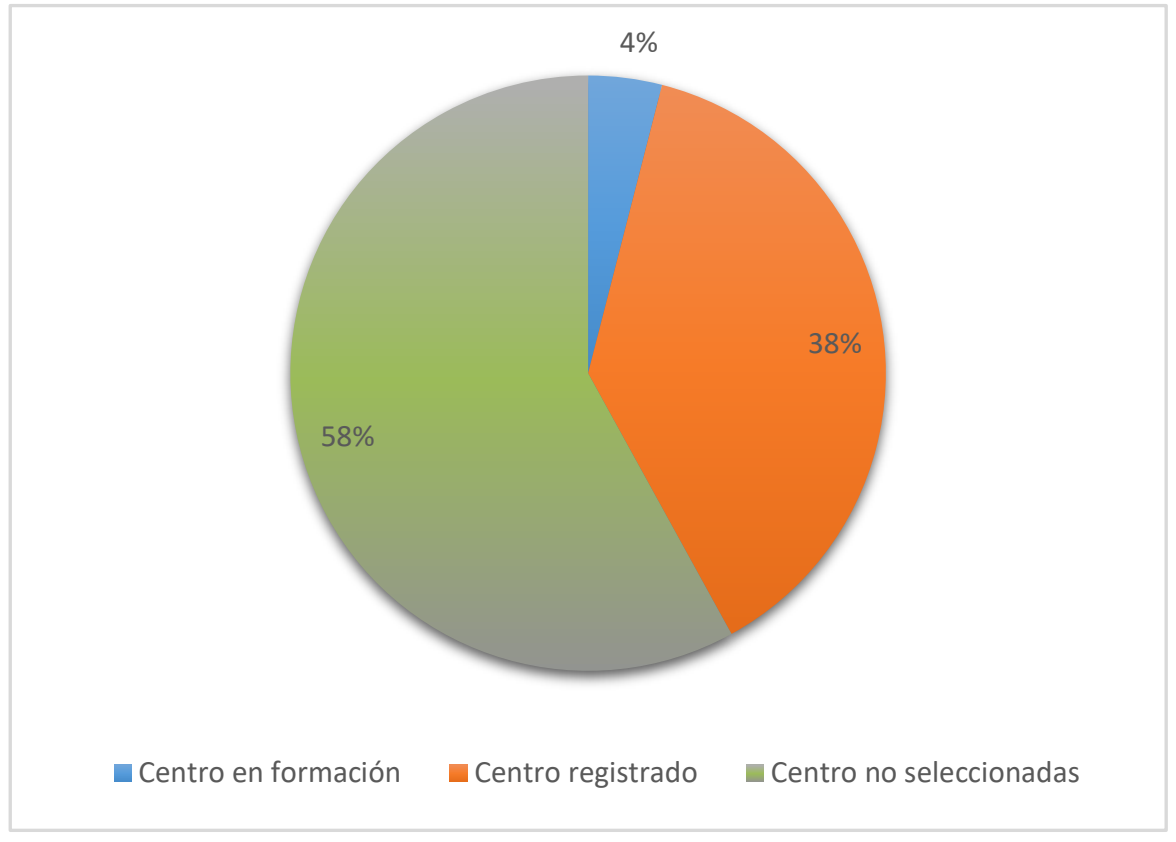

Fuente: Encuesta sobre el desarrollo de instituciones de estudios latinoamericanos en China (1949-2019), Asociación China de Estudios Latinoamericanos, 2019.

En segundo lugar, un $43 \%$ de los centros de estudios latinoamericanos creados pertenecen a plataformas de nivel escolar y académico. Estos son la mayoría ( ver Gráfico 1-6 ). Estas instituciones de nivel académico a grandes rasgos incluyen dos tipos principales: bien son de presencia física y, por tanto, no dependen de otro departamento o facultad; o bien pertenecen al tipo de "cargo bajo, asignación alta" (di zhi gao pei). Es decir, que pese a pertenecer a una plataforma de nivel académico, su desarrollo aún depende principalmente de una facultad de lenguas extranjeras o de asuntos internacionales. Además de estos, los centros de estudios latinoamericanos aún dependen de los siguientes tipos de facultades:

Orientando. Temas de Asia Oriental. Sociedad, Cultura y Economía. Revista editada por el Centro de Estudios China-Veracruz de la Universidad Veracruzana, México (Centro de Estudios APEC) / año 10 / número 19/ 
lenguas extranjeras $(21 \%)$, asuntos internacionales ( $13 \%$ ), dirección y gestión e historia (ambas en torno a un 9\%), etc. También hay una minoría que depende de facultades de antropología, sociología, políticas y la administración pública, etc. Este tipo de distribución ha influido relativamente los campos de investigación y estudio.

Gráfico 1-6. Distribución de instituciones de estudios latinoamericanos en China según dependencia por facultades ${ }^{(1)}$

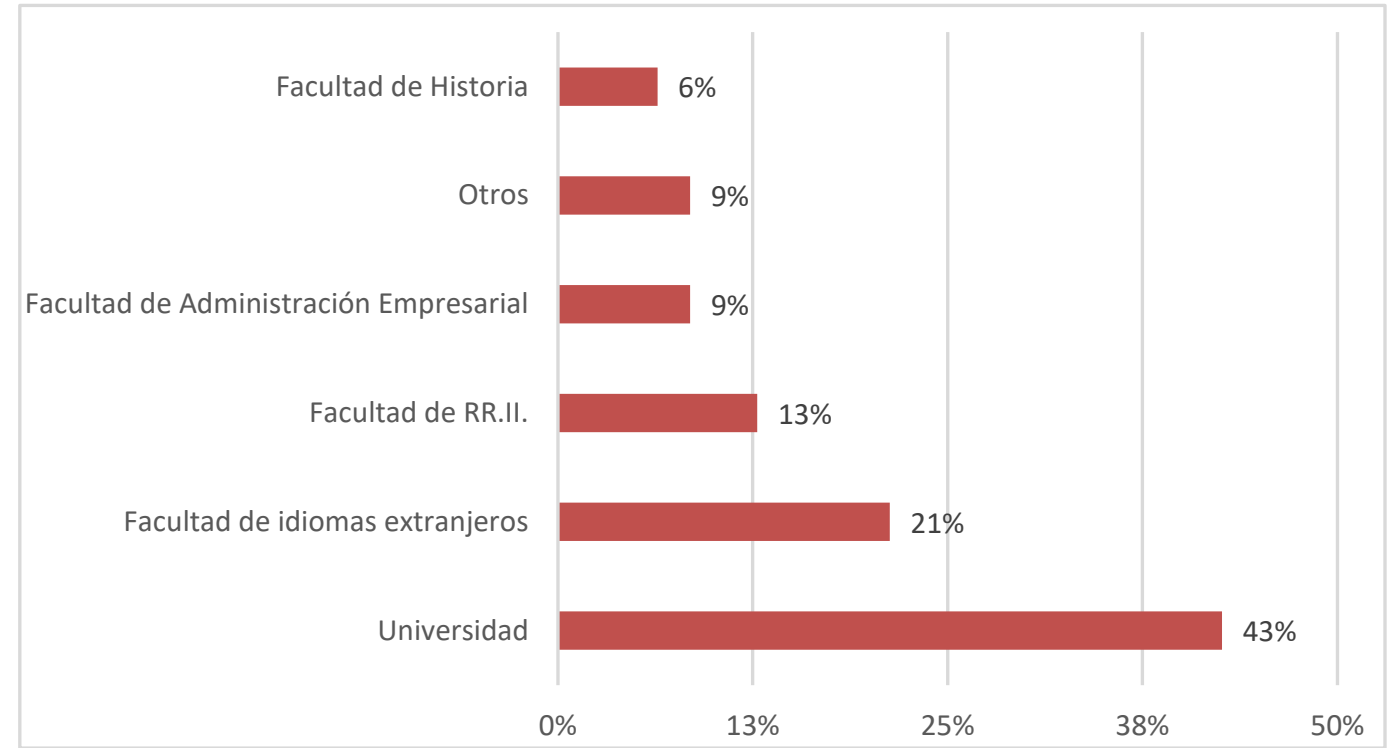

Fuente: Encuesta sobre el desarrollo de instituciones de estudios latinoamericanos en China (1949-2019), Asociación China de Estudios Latinoamericanos, 2019.

La naturaleza de los centros de investigación y su selección o no en la lista de centros de formación o centros admitidos a trámite para la enseñanza de estudios nacionales comparativos y regionales del Ministerio de Educación, influye en el grado de importancia concedida por los centros de educación superior a las instituciones dedicadas a los estudios latinoamericanos, así como su asignación de recursos financieros.

\footnotetext{
(1) Las estadísticas solo incluyen aquí las 53 instituciones que contestaron válidamente los cuestionarios.
}

Orientando. Temas de Asia Oriental. Sociedad, Cultura y Economía. Revista editada por el Centro de Estudios China-Veracruz de la Universidad Veracruzana, México (Centro de Estudios APEC) / año 10 / número 19/ 
De los 53 cuestionarios válidos, tan sólo 25 instituciones ( un 47\% ) tienen presupuestos anuales, más de la mitad de ellas ( 28 instituciones ) no tienen presupuesto anual. ${ }^{(1)}$ La carencia de un presupuesto anual generalmente es indicativa de que es difícil realizar un plan de investigación científica, por lo que la viabilidad de la investigación científica se convierte en un problema. Un análisis más profundo de las 25 instituciones que tienen un presupuesto anual esclarece la situación de estas instituciones.

Como se observa en el Gráfico 1-7, cualquier institución de estudios latinoamericanos que cuenta con presupuesto anual, un $44 \%$ de ellas, tienen un presupuesto entre 200 mil y 300 mil yuanes o mayor. A pesar de ello, aún hay un $28 \%$ de las instituciones cuyo presupuesto se sitúa por debajo de los 100 mil yuanes. De las instituciones de estudios latinoamericanos que no tienen un presupuesto anual, ( ver Gráfico 1-8 ), casi un $80 \%$ de ellas tienen un presupuesto anual por debajo de los 200 mil yuanes; y más de la mitad( $54 \%$ ) tienen un presupuesto anual que no llega a los 50 mil yuanes. Por tanto, podemos observar que la falta de presupuesto anual, generalmente indica que hay insuficiencia de fondos o que la sostenibilidad de la institución está comprometida. Esto influye el impulso y los frutos de los estudios latinoamericanos.

\footnotetext{
(1)Tener un presupuesto indica una estabilización y sistematización del apoyo financiero. Generalmente, se establecen el presupuesto y las partidas de gastos en el año anterior. No tener un presupuesto indica que los gastos de la investigación no pueden tener un sistema de garantía, aunque tampoco es indicativo de que no reciben ningún apoyo financiero. La diferencia es que al "carecer de presupuesto" los gastos de las actividades académicas o proyectos generalmente se solicitan con poca antelación, limitando la cantidad disponible.
}

Orientando. Temas de Asia Oriental. Sociedad, Cultura y Economía. Revista editada por el Centro de Estudios China-Veracruz de la Universidad Veracruzana, México (Centro de Estudios APEC) / año 10 / número 19/ 
Gráfico 1-7. Proporción de instituciones de estudios latinoamericanos con presupuesto: según su presupuesto anual

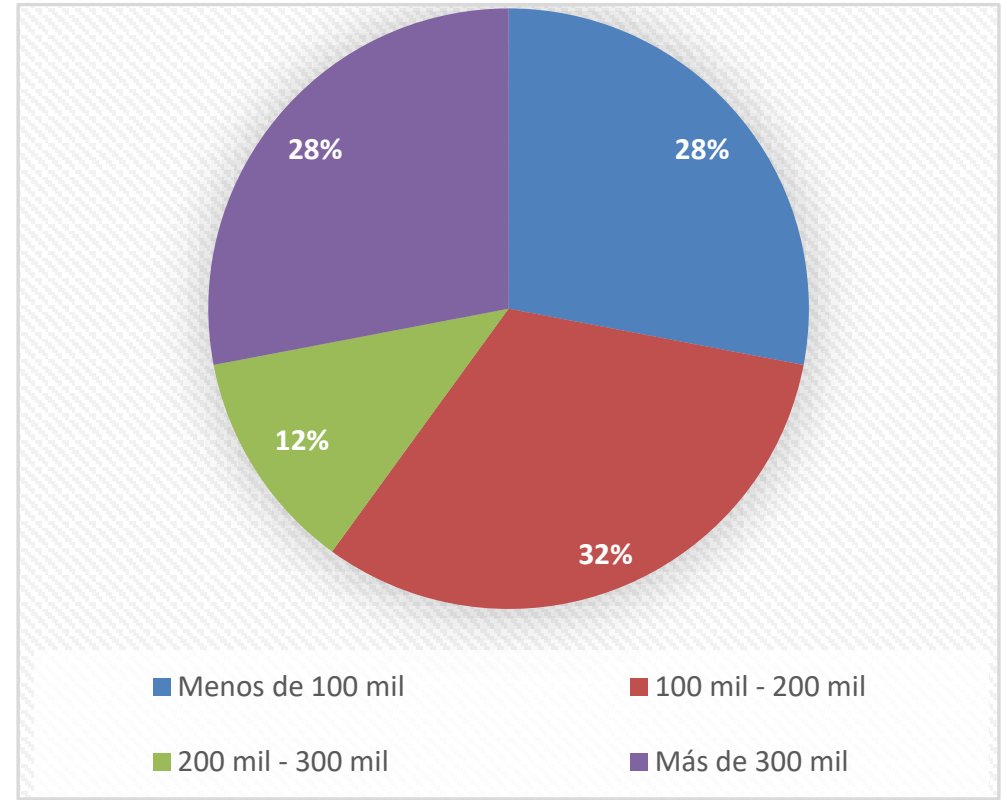

Fuente: Encuesta sobre el desarrollo de instituciones de estudios latinoamericanos en China (1949-2019), Asociación China de Estudios Latinoamericanos, 2019.

Orientando. Temas de Asia Oriental. Sociedad, Cultura y Economía. Revista editada por el Centro de Estudios China-Veracruz de la Universidad Veracruzana, México (Centro de Estudios APEC) / año 10 / número 19/ 
Gráfico 1-8. Proporción de instituciones de estudios latinoamericanos sin presupuesto: según su presupuesto anual

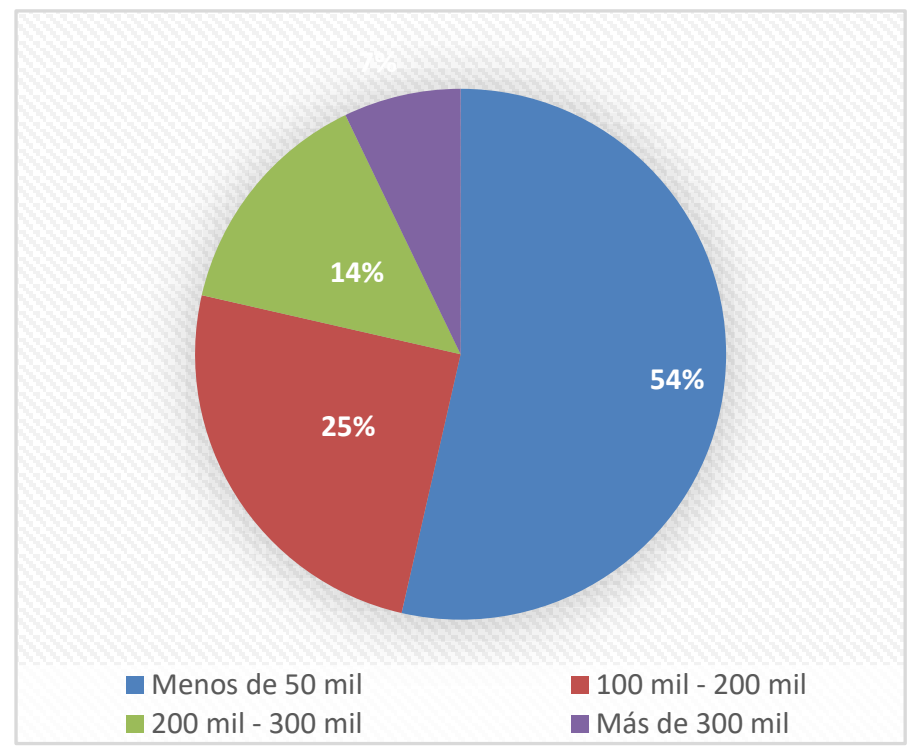

Fuente: Encuesta sobre el desarrollo de instituciones de estudios latinoamericanos en China (1949-2019), Asociación China de Estudios Latinoamericanos, 2019.

( 4 ) La formación de los investigadores en términos generales ha mejorado, aunque la

Orientando. Temas de Asia Oriental. Sociedad, Cultura y Economía. Revista editada por el Centro de Estudios China-Veracruz de la Universidad Veracruzana, México (Centro de Estudios APEC) / año 10 / número 19/ 
situación general aún es mejorable

En comparación con el año 2000, bien sea en el nivel de formación académica, idiomas extranjeros o perfil académico, etc., la formación general de los actuales investigadores de Latinoamérica ha mejorado visiblemente, aunque aún existe margen para mejorar con respecto a su situación general.

En primer lugar, hay un desequilibrio entre los investigadores a tiempo completo y parcial. En el contexto de mejora de las relaciones entre China y Latinoamérica y gracias al impulso de las políticas mencionadas anteriormente, se encuentra el "gran salto hacia delante" en las instituciones de estudios latinoamericanos. Sin embargo, los investigadores que sostienen estas instituciones no han avanzado de la misma manera. Al fin y al cabo, la formación del talento no se consigue de inmediato, sino que se requiere un proceso relativamente largo.

Algunas instituciones, pese a no tener ninguna base de investigación académica o investigadores relevantes, bien han sido arrastradas por "la moda de los estudios latinoamericanos", o bien han aprovechado ocupar el espacio abierto anunciando su creación. Incluso hay algunas que han entrado directamente a la lista de admitidos -en cierta medida, esto explica por qué tan solo en 2017 hubo un aumento de hasta 14 nuevas instituciones. Esto ha conducido el desarrollo de los estudios latinoamericanos en China a una "situación extraña" (guai zhuang): existen pocas instituciones que sólo tiene el título sin personal, o sólo tiene títulos y nombres de personal, unas instituciones relativamente mejores han adoptado personal "a tiempo y a tiempo parcial" para adecuarse a la embarazosa falta de investigadores actual.

No obstante, algunas instituciones dependen completamente de personal a tiempo parcial, con lo que su principal problema resulta ser que algunos investigadores a tiempo parcial son en realidad "aficionados" (jian er $b u$ zhi), que ni siquiera han producido contenido académico. La información y estadísticas válidas aportadas por 46 instituciones

Orientando. Temas de Asia Oriental. Sociedad, Cultura y Economía. Revista editada por el Centro de Estudios China-Veracruz de la Universidad Veracruzana, México (Centro de Estudios APEC) / año 10 / número 19/ 
demuestra que , dentro del total de 552 investigadores que prestaron declaración, hay un $30 \%$ que son investigadores a tiempo completo, equivalente a 163 investigadores; así, hay 389 que lo son a tiempo parcial, un $70 \%$ ( ver Gráfico 1 - 9 ) . (1)

Un análisis aún más específico, demuestra que si excluyendo a los 62 investigadores a tiempo completo de las 6 instituciones que no pertenecen a centros de educación superior o think tanks (2), cada institución de enseñanza superior dedicada a los estudios latinoamericanos tiene una media inferior a 3 investigadores a tiempo completo. De estas instituciones, hay 13 que ni siquiera tienen personal a tiempo completo.

\section{Gráfico 1-9. Proporción de investigadores de tiempo completo y tiempo parcial}

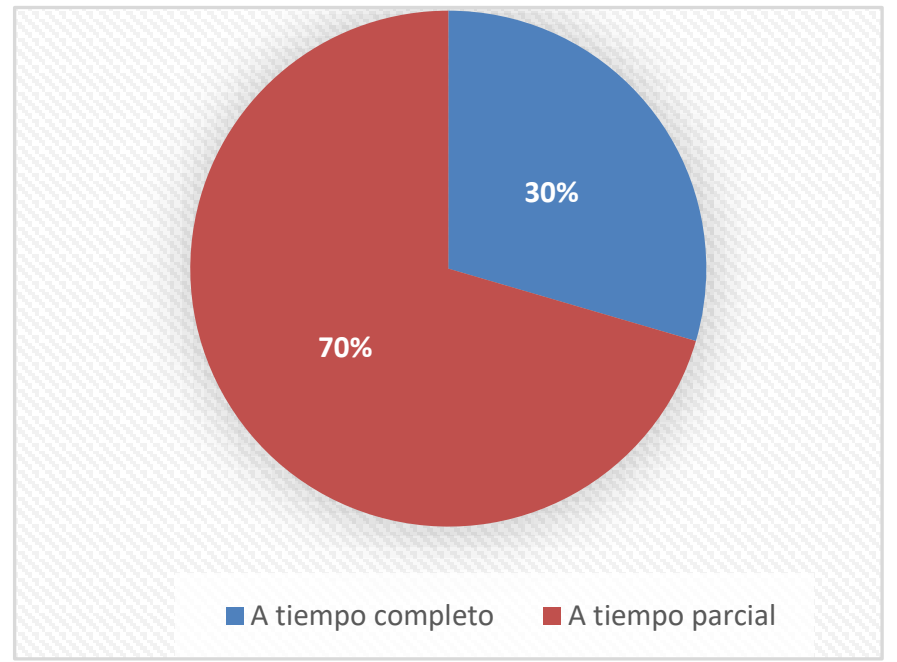

Fuente: Encuesta sobre el desarrollo de instituciones de estudios latinoamericanos en China

(1) Las instituciones individuales que han sido encuestadas pueden haber entendido mal las diferencias fundamentales entre los trabajos a tiempo completo y a tiempo parcial, por lo que la brecha entre los datos informados y los hechos es grande porque es completamente incompatible con la cantidad de resultados de investigaciones científicas informados. Se excluyen las instituciones de investigación que tienen una gran cantidad de trabajos de tiempo completo y que son inconsistentes con los hechos, dejando solo 46 instituciones que son relativamente efectivas. Los Gráficos 1-12 y 1-14 toman el número de 46 instituciones.

(2) Incluye el Instituto Latinoamericano de la Academia China de Ciencias Sociales y la Oficina de Investigación de Historia Latinoamericana del Instituto de Historia Mundial, el Instituto Latinoamericano del Instituto de Relaciones Internacionales Contemporáneas de China, el Instituto de Estudios Latinoamericanos y del Caribe del Instituto de Estudios Internacionales de China, el Instituto de Comercio y el Instituto de América y Oceanía, así como el Centro de Estudios Americanos del Instituto de Estudios Internacionales de Shanghái.

Orientando. Temas de Asia Oriental. Sociedad, Cultura y Economía. Revista editada por el Centro de Estudios 
(1949-2019), Asociación China de Estudios Latinoamericanos, 2019.

En segundo lugar, la formación académica de los investigadores, sus cargos y su conocimiento de idiomas extranjeros en general conforman una tendencia relativamente mejor.

Un amplio currículo académico, altos cargos y alto nivel de idiomas extranjeros son las condiciones fundamentales y obstáculos básicos para desarrollar un círculo académico de estudios latinoamericanos de calidad. Desde todas las perspectivas, la tendencia actual es positiva en relación con el desempeño de los investigadores de Latinoamérica en tales aspectos.

Con respecto al currículo académico, más de la mitad ( un 54\% ) de los investigadores poseen un doctorado; un 33\% de los investigadores han obtenido un máster; $\mathrm{y}$, pese a todo, aún hay un 13\% de los investigadores que solo poseen un título de grado （ver Gráfico 110 ). Esto indica que, aunque los estudiosos de Latinoamérica en términos generales poseen una formación académica relativamente buena, aún hay una necesidad urgente entre una proporción significativa de los investigadores de mejorar su nivel de formación académica.

No obstante, esta situación ya ha mejorado mucho con respecto al año 2000. Asimismo, la formación académica de los profesores de español cualificados es mejor en comparación. Según las estadísticas del profesor Zheng Shujiu ${ }^{(1)}$, en 2018, de los 799 profesores de español de China solo un 32,1\% de ellos poseían un doctorado o estaban cursando un doctorado actualmente y cerca de un $70 \%$ solo tenían un título de máster.

(1) Libro editado por Zheng Shujiu. (2015). Investigación sobre la enseñanza del español en los centros de educación superior nacionales (《全国高等院校西班牙语教育研究》). Beijing: Editorial de Enseñanza e Investigación de Lenguas Extranjeras. Datos posteriormente actualizados por el profesor Zheng Shujiu tras la revisión del informe.

Orientando. Temas de Asia Oriental. Sociedad, Cultura y Economía. Revista editada por el Centro de Estudios China-Veracruz de la Universidad Veracruzana, México (Centro de Estudios APEC) / año 10 / número 19/ 


\section{Gráfico 1-10. Formación académica de los investigadores}

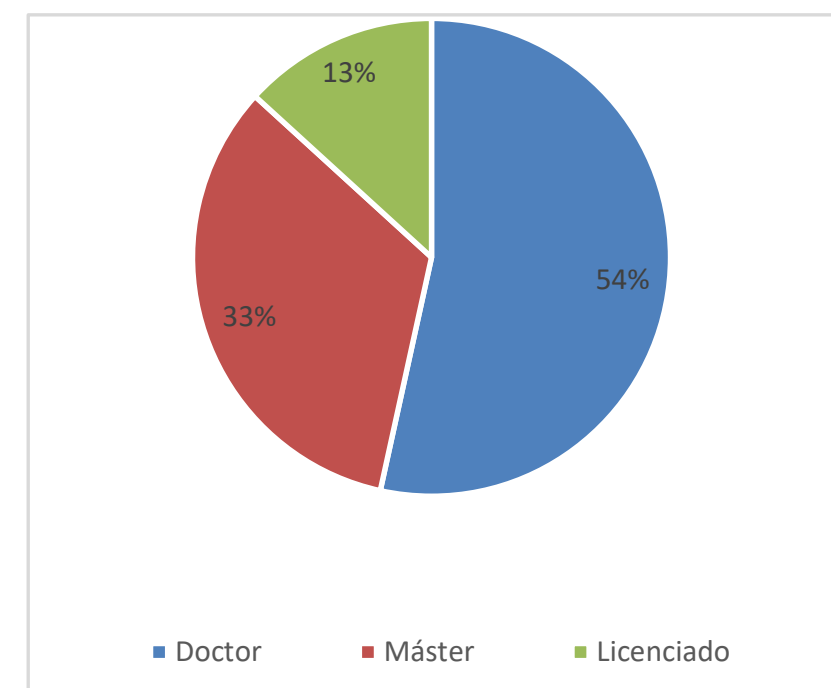

Fuente: Encuesta sobre el desarrollo de instituciones de estudios latinoamericanos en China (1949-2019), Asociación China de Estudios Latinoamericanos, 2019.

Los cargos profesionales de los investigadores de Latinoamérica también presentan grandes similitudes ( ver Gráfico 1-11). Los investigadores que ostentan un cargo profesional de catedrático o investigador académico son un $28 \%$, mientras que los que ocupan un cargo de profesor o investigador adjuntos son un $24 \%$, ambos representando el $52 \%$ del total. Es decir, más de la mitad de los investigadores de Latinoamérica ostentan un cargo en instituciones de enseñanza superior.

Esta proporción es mucho más alta que aquella relativa a los profesores cualificados de español. En 2018, los profesores cualificados de español que ostentan un cargo de catedrático o profesor universitario adjunto representan tan solo representan un $4 \%$ y un $10 \%$ respectivamente, un total por debajo del 15\% (1). No obstante, los investigadores de estudios latinoamericanos y los profesores cualificados de español que ostentan un cargo de nivel intermedio tienen una proporción similar, un $43 \%$ y un 53\%, respectivamente. Esto

(1) Ibíd.

Orientando. Temas de Asia Oriental. Sociedad, Cultura y Economía. Revista editada por el Centro de Estudios China-Veracruz de la Universidad Veracruzana, México (Centro de Estudios APEC) / año 10 / número 19/ 
demuestra completamente que, los cargos que ostentan los investigadores de Latinoamérica, pese a estar en mejor situada en comparación a los profesores cualificados de español, aún mantiene un gran margen para mejorar.

Gráfico 1-11. Estructura de los cargos ostentados por el personal investigador

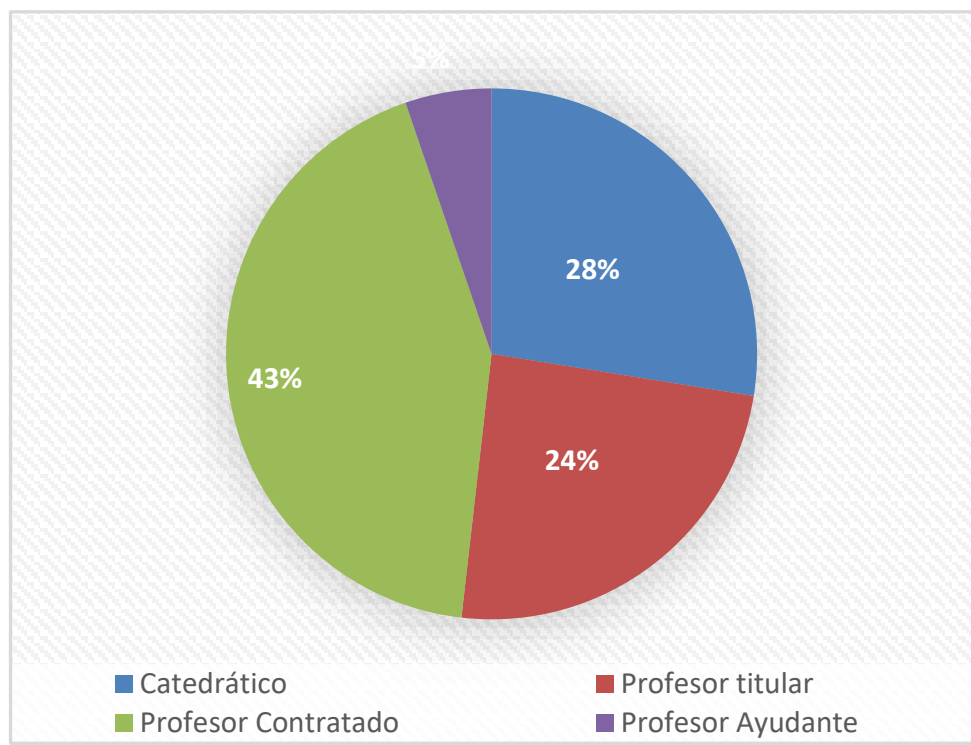

Fuente: Encuesta sobre el desarrollo de instituciones de estudios latinoamericanos en China (1949-2019), Asociación China de Estudios Latinoamericanos, 2019.

Orientando. Temas de Asia Oriental. Sociedad, Cultura y Economía. Revista editada por el Centro de Estudios China-Veracruz de la Universidad Veracruzana, México (Centro de Estudios APEC) / año 10 / número 19/ 
El conocimiento de idiomas extranjeros cubre las necesidades básicas del estudio académico de Latinoamérica. El conocimiento de idiomas extranjeros es una capacidad fundamental para dedicarse a los estudios regionales. Saber inglés, y especialmente saber español y portugués, resultan habilidades indispensables para investigar en profundidad la región de Latinoamérica. Con respecto a la actual situación del conocimiento de idiomas extranjeros, aún hay mucho margen para mejora, aunque ya ha habido grandes progresos. Inicialmente, ha habido avances suficientes para satisfacer los requisitos para dedicarse al estudio académico de Latinoamérica.

La investigación demuestra que casi la mitad de los investigadores (un 47\%) habla inglés, pero los que hablan español y portugués, representan solo un $21 \%$ y $7 \%$, respectivamente. Con respecto a los investigadores que dominan dos idiomas extranjeros ( inglés y español, o inglés y portugués, o español y portugués ), estos representan un $25 \%$ de los investigadores ( ver Gráfico 1-12). No obstante, es necesario apuntar que un escenario más ideal sería donde los investigadores dominasen el inglés y además dominasen el idioma principal del sujeto de investigación -bien español o portugués. Esto deberían ser los requisitos básicos o, quizás, los más altos para aquellos que deseen dedicarse a los estudios latinoamericanos. Actualmente, aún falta mucho para conseguir llegar a este objetivo.

\section{Gráfico 1-12: Conocimientos de idiomas extranjeros de los investigadores de} Latinoamérica

Orientando. Temas de Asia Oriental. Sociedad, Cultura y Economía. Revista editada por el Centro de Estudios China-Veracruz de la Universidad Veracruzana, México (Centro de Estudios APEC) / año 10 / número 19/ 


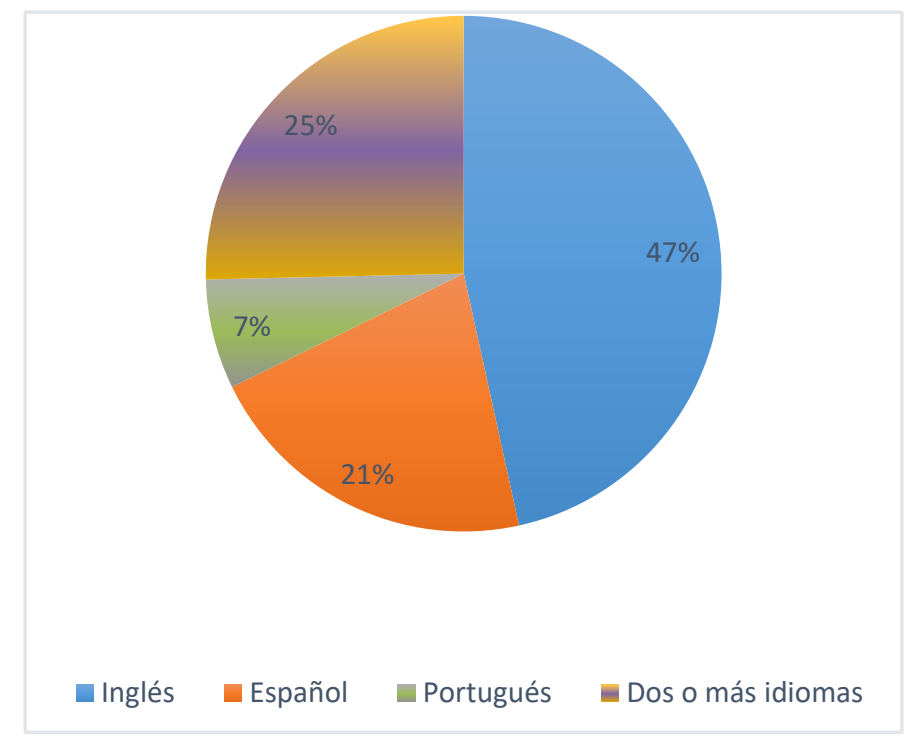

Fuente: Encuesta sobre el desarrollo de instituciones de estudios latinoamericanos en China (1949-2019), Asociación China de Estudios Latinoamericanos, 2019.

Las edades de los investigadores de la región han mejorado, se ha cerrado bastante la brecha de edad del talento ( ver Gráfico 1-13 ) . Con respecto a las edades, actualmente, la juventud se ha convertido en la principal fuerza que impulsa los estudios latinoamericanos. La aparición de brechas entre los grupos de edades de los investigadores de Latinoamérica que ocurría frecuentemente antes ha sido aliviada. Los jóvenes investigadores de entre 3049 años representan el 61\%, de los cuales aquellos entre 30-39 años son la mayoría, un $34 \%$, frente a un 27\% de los del tramo de 40-49 años. Estos tramos de edad ofrecen mayores garantías para la continuidad de la investigación y estudio de la región.

\section{Gráfico 1-13. Estructura de las edades de los investigadores de Latinoamérica}

Orientando. Temas de Asia Oriental. Sociedad, Cultura y Economía. Revista editada por el Centro de Estudios China-Veracruz de la Universidad Veracruzana, México (Centro de Estudios APEC) / año 10 / número 19/ 


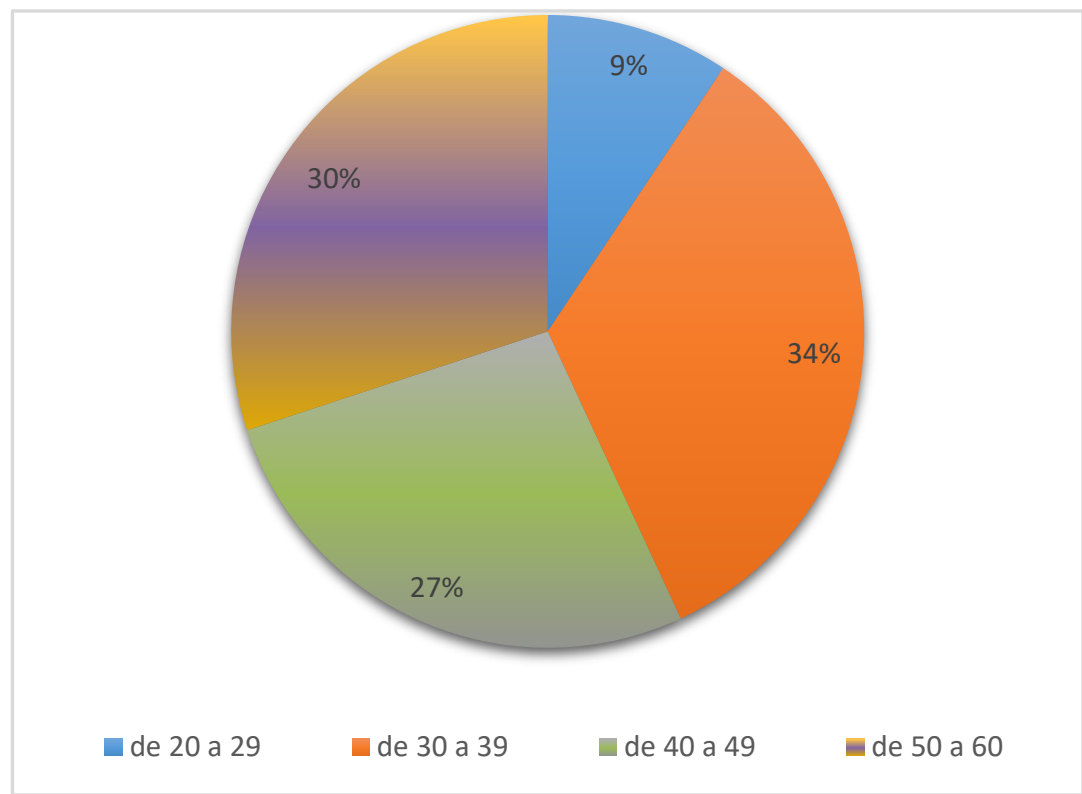

Fuente: Encuesta sobre el desarrollo de instituciones de estudios latinoamericanos en China (1949-2019), Asociación China de Estudios Latinoamericanos, 2019.

El perfil académico de los investigadores de Latinoamérica está cambiando de las tradicionales asignaturas a cada día un perfil más diverso. Tradicionalmente, la mayoría de los investigadores de Latinoamérica habían estudiado alguna lengua extranjera, historia y política (internacional), tales asignaturas. Por tanto, limitaban la capacidad del estudio multidisciplinar e integral de Latinoamérica. Objetivamente, también dificultaba satisfacer las necesidades reales del estudio de Latinoamérica.

Especialmente, tras la entrada al siglo XXI, los jóvenes continúan siendo con fuerza la sangre fresca de las instituciones de estudios latinoamericanos, uniéndose a sus equipos. También están promoviendo el desarrollo del perfil académico de los investigadores de Latinoamérica hacia uno más diverso ( ver Gráfico 1-14 ) . En primer lugar, no ha habido cambios claros en las tradicionalmente asignaturas con ventaja: la literatura y el derecho ${ }^{(1)}$

\footnotetext{
(1) El diseño del cuestionario del perfil académico se basa en la clasificación legal de las materias. La ley aquí se refiere principalmente a la disciplina de ciencias políticas de primer nivel (0302), que incluye principalmente 8 disciplinas de segundo nivel: teoría política, sistemas políticos de China y del extranjero, socialismo científico y comunismo, historia del Partido Comunista, teoría marxista y educación ideológica y política, la política internacional, las relaciones internacionales y la diplomacia.
}

Orientando. Temas de Asia Oriental. Sociedad, Cultura y Economía. Revista editada por el Centro de Estudios China-Veracruz de la Universidad Veracruzana, México (Centro de Estudios APEC) / año 10 / número 19/ 
-que aún siguen siendo los principales perfiles académicos, con un $33,5 \%$ y un $26,4 \%$ de los perfiles de investigadores.

No obstante, la historia, que tradicionalmente era un perfil prevalente, ha decaído y ahora tan solo es el perfil de un $13 \%$. En segundo lugar, la economía, la docencia y la administración (de empresas), etc., son perfiles emergentes, que han pasado a tener una posición importante y a ser el principal perfil suplementario. Por ejemplo, los investigadores con un perfil de economía llegan al 18,7\%, mientras que aquellos con un perfil de docencia o administración representan el 1,4\% y el 4\%, respectivamente. Estos cambios han enriquecido y actualizado en gran medida el perfil académico de los investigadores de Latinoamérica y también resulta ser beneficioso para la estructura de contenidos de los estudios latinoamericanos.

\section{Gráfico 1-14. Perfil académico de los investigadores de Latinoamérica en China}

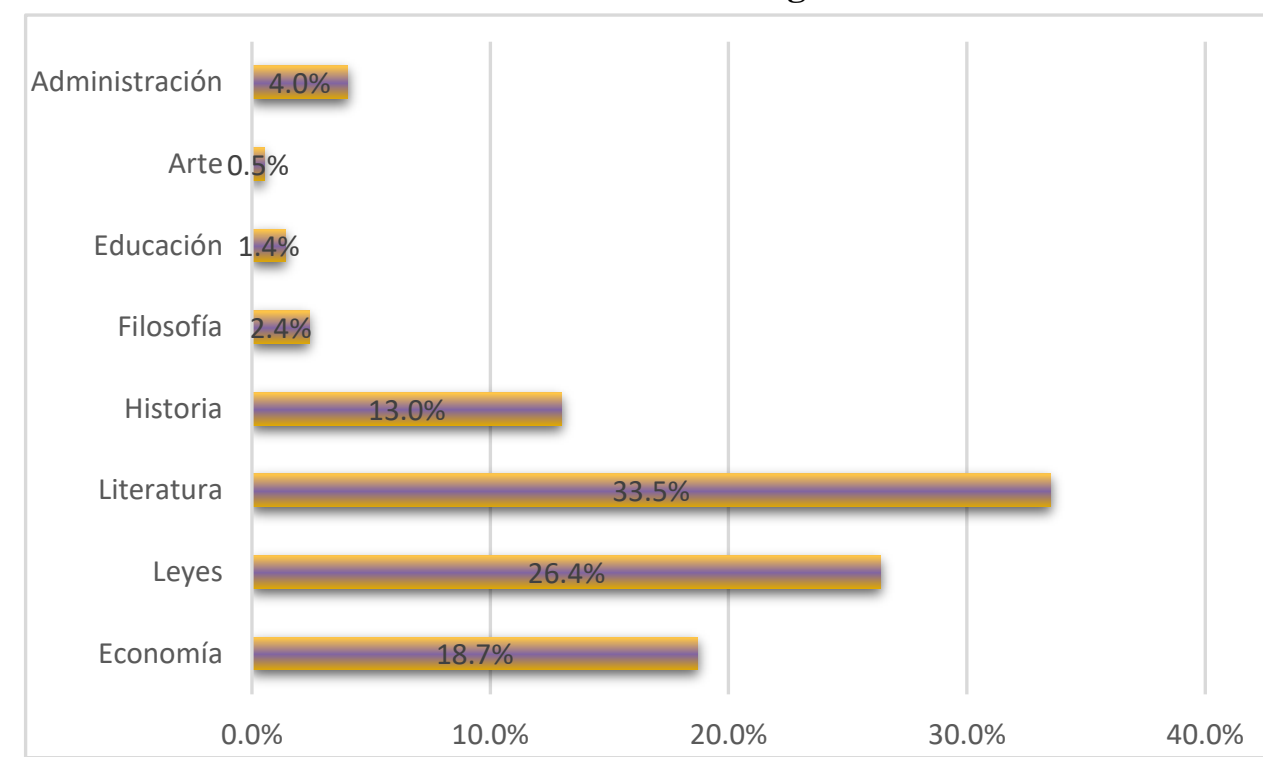

Fuente: Encuesta sobre el desarrollo de instituciones de estudios latinoamericanos en China (1949-2019), Asociación China de Estudios Latinoamericanos, 2019.

La experiencia en disciplinas académicas cada día es más diversa y, en cierta medida, está promoviendo que las materias de estudio e investigación sean más variadas. Según las declaraciones de las instituciones encuestadas (ver Gráfico 1-15) , a pesar de que la

Orientando. Temas de Asia Oriental. Sociedad, Cultura y Economía. Revista editada por el Centro de Estudios China-Veracruz de la Universidad Veracruzana, México (Centro de Estudios APEC) / año 10 / número 19/ 
política, la economía y las relaciones internacionales aún continúen siendo los tres principales campos tradicionales de investigación, con un 13\%, 14,9\% y un 15,8\%, respectivamente; ha empezado a haber un mayor interés por los campos anteriormente menos investigados, como la sociología o la cultura, etc, con un $12,7 \%$ y un $15,4 \%$, respectivamente. Esto indica que en relación a la investigación fuera de estas materias relativamente más prácticas, las instituciones de investigación han comenzado a entender la importancia de la creación de conocimiento y han dedicado mayores esfuerzos a investigar otras materias menos comunes o clásicas.

A pesar de que el estudio de Latinoamérica en China originó en el estudio de su historia, actualmente no hay mucha vinculación entre el estudio de historia latinoamericana y las necesidades reales. Por tanto, nunca ha sido un campo de estudio muy demandado, tan solo representando un $12,4 \%$. Sin embargo, algo lo bueno es que el ámbito de los estudios latinoamericanos se está expandiendo constantemente, llegando a incluir materias como el derecho $(0,9 \%)$, el arte $(2,2 \%)$, la religión $(2,2 \%)$, la antropología $(3,1 \%)$, materias que cada vez son de mayor interés para los jóvenes investigadores. Dado que los nuevos investigadores, las nuevas instituciones y las nuevas materias reflejan un estancamiento relativo en la producción académica, no se pueden cambiar de inmediato los frutos de la investigación, pero podemos imaginar que, en el futuro, los logros académicos de los estudios latinoamericanos serán más amplios y diversos.

Orientando. Temas de Asia Oriental. Sociedad, Cultura y Economía. Revista editada por el Centro de Estudios China-Veracruz de la Universidad Veracruzana, México (Centro de Estudios APEC) / año 10 / número 19/ 
Gráfico 1-15. Distribución de materias de investigación de interés de las instituciones de estudios latinoamericanos en China

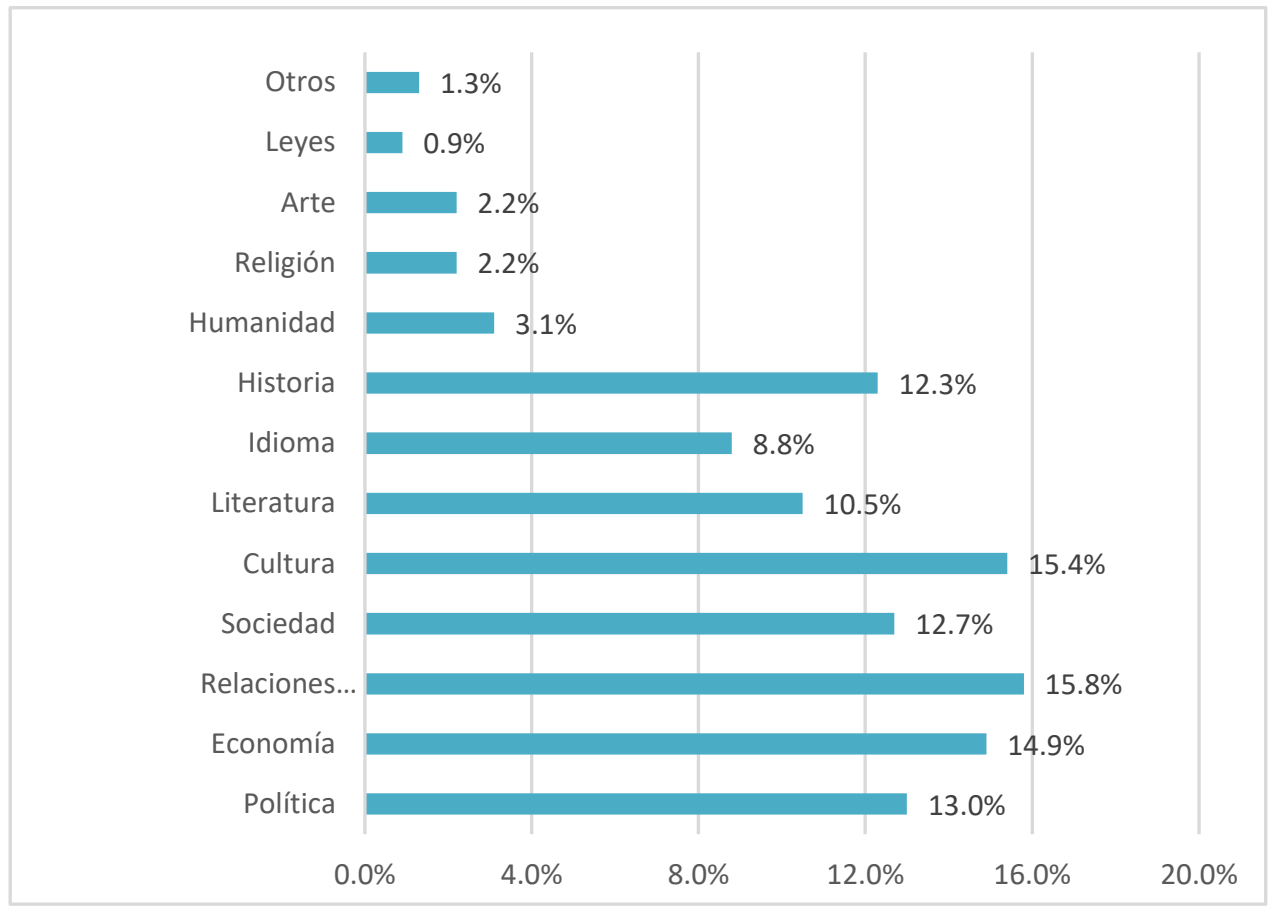

Fuente: Encuesta sobre el desarrollo de instituciones de estudios latinoamericanos en China (1949-2019), Asociación China de Estudios Latinoamericanos, 2019.

( 5 ) La actividad de las instituciones no es tan alta, la promoción y concienciación de los resultados es mejorable

Pese a que en los últimos años las instituciones de estudios latinoamericanos en China se han desarrollado continuamente, la actividad académica de estas instituciones no es muy elevada y la promoción y concienciación de los resultados o sus actividades son generalmente bajos. La investigación demuestra que , casi un 60\% de las instituciones organiza de media una conferencia académica al año, mientras que tan solo un $30 \%$ organizan dos reuniones académicas al año ( ver Gráfico 1-16 ). Organizar conferencias

Orientando. Temas de Asia Oriental. Sociedad, Cultura y Economía. Revista editada por el Centro de Estudios China-Veracruz de la Universidad Veracruzana, México (Centro de Estudios APEC) / año 10 / número 19/ 
académicas y la exploración de cuestiones académicas son algunas de las actividades funcionales más importantes de tales instituciones. La insuficiente actividad académica claramente no beneficia a la creación ni desarrollo del entorno académico de estas instituciones. No obstante, esto quizás se deba a la falta de presupuestos anuales o de la relativa restricción de gastos de estas instituciones, mencionadas anteriormente, o incluso su falta de personal institucional, lo que dificulta organizar conferencias académicas de determinado tamaño.

Gráfico 1-16. Número de conferencias académicas al año organizadas por las instituciones investigadas

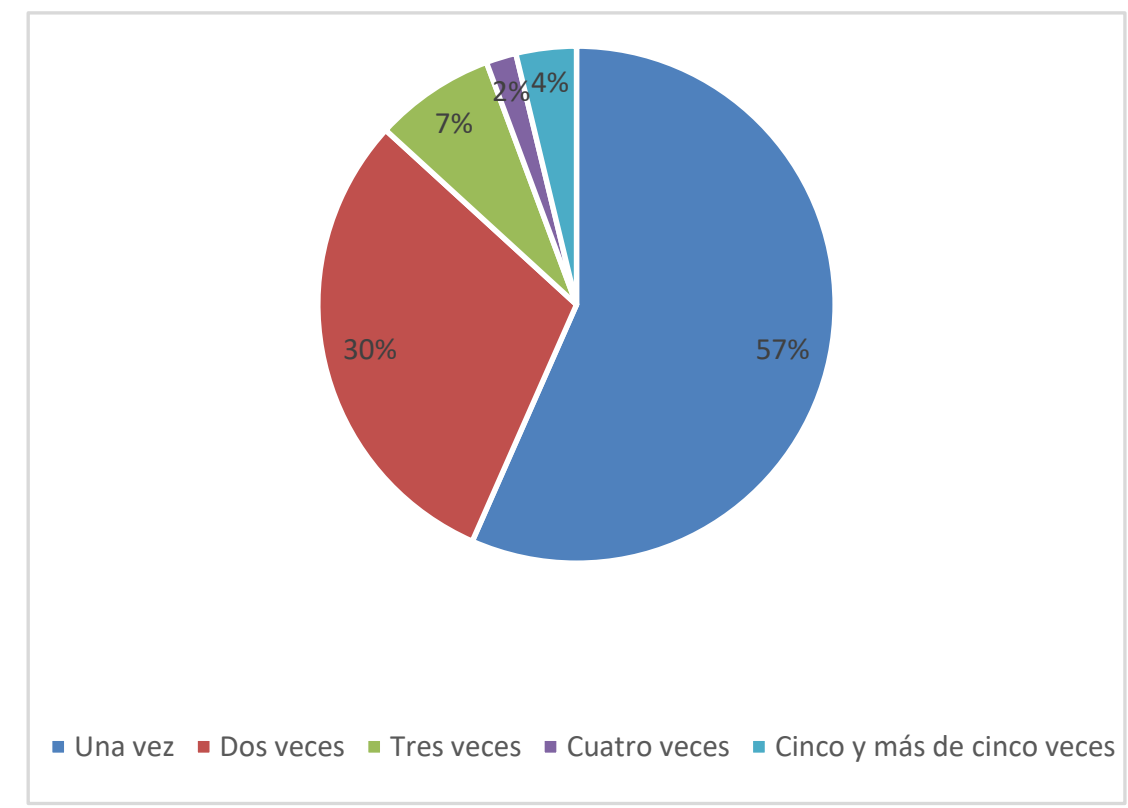

Fuente: Encuesta sobre el desarrollo de instituciones de estudios latinoamericanos en China (1949-2019), Asociación China de Estudios Latinoamericanos, 2019.

En comparación con las conferencias académicas, las ponencias y charlas académicas son mucho más convenientes y rápidas, tienen menores costes, y por tanto, son mucho más fáciles de realizar. Como demuestra el Gráfico 1-17 ,un 44\% de las instituciones de estudios latinoamericanos organiza una media anual de 4-6 ponencias académicas, incluso un $22 \%$ de las instituciones organizan más ponencias y charlas: un $12 \%$ organiza 10 o más ponencias al año, y un 10\% organiza entre 7-9 charlas y ponencias al año. El incremento

Orientando. Temas de Asia Oriental. Sociedad, Cultura y Economía. Revista editada por el Centro de Estudios China-Veracruz de la Universidad Veracruzana, México (Centro de Estudios APEC) / año 10 / número 19/ 
relativo en el número de ponencias académicas es altamente beneficioso para la difusión de los conocimientos sobre Latinoamérica, pero, al mismo tiempo, demuestra que muchas instituciones dependen excesivamente en organizar este tipo de eventos académicos para reforzar su presencia.

\section{Gráfico 1-17. Número medio de ponencias y charlas académicas organizadas cada año por las instituciones investigadas}

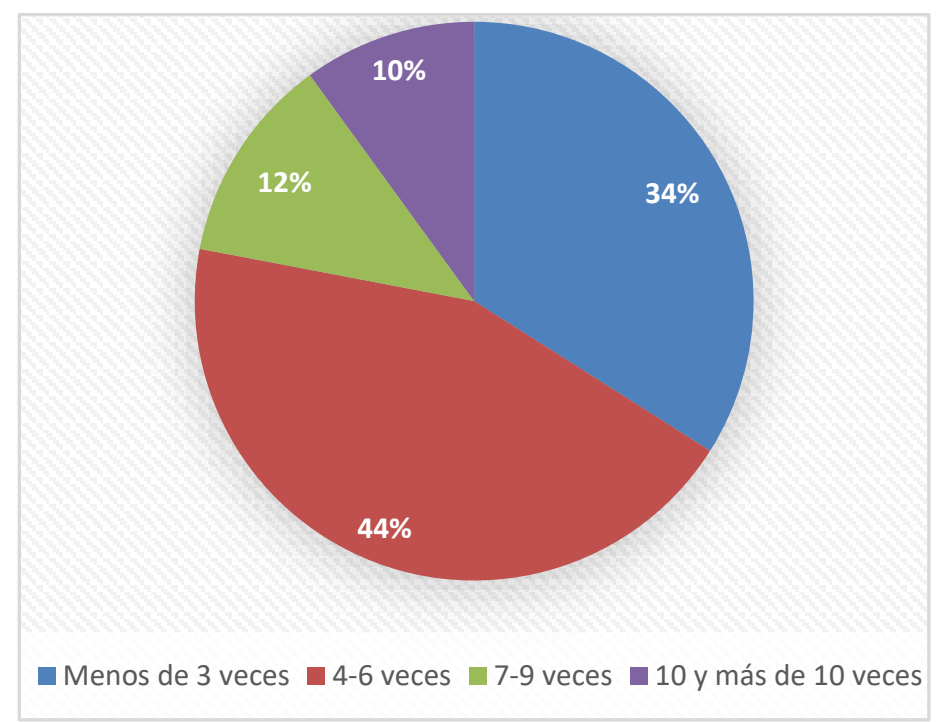

Fuente: Encuesta sobre el desarrollo de instituciones de estudios latinoamericanos en China (1949-2019), Asociación China de Estudios Latinoamericanos, 2019.

Pese a que la actividad académica no es muy alta, algo tranquilizador es que es que los logros académicos de las instituciones no son menores. De las 53 instituciones entrevistadas, ( teniendo en cuenta que muchas son de reciente creación ), no solo ha habido buenos resultados con respecto al desempeño académico, sino que los logros académicos también han sido relativamente variados ( ver Gráfico 1-18). Según las estadísticas, las 53 instituciones han declarado haber producido conjuntamente un total de 504 artículos académicos de todas las disciplinas, una media de 9,5 por cada institución. De ellos, 302 se han escrito en chino, un 59,9\%; mientras que 120 han sido escritos en idiomas extranjeros, un 23,8\%; se han escrito hasta 30 libros especializados, un 6\%; y hasta 25 libros traducidos,

Orientando. Temas de Asia Oriental. Sociedad, Cultura y Economía. Revista editada por el Centro de Estudios China-Veracruz de la Universidad Veracruzana, México (Centro de Estudios APEC) / año 10 / número 19/ 
un 5\%; se han editado 27 libros, un 5,4\%. Lo que hace levantar sospechas es que, hay hasta 120 textos en idiomas extranjeros, una cifra que no parece muy fiable. Más concretamente, se ha descubierto que algunas instituciones de estudios latinoamericanos constituidas recientemente han contratado directamente a académicos de Latinoamérica o investigadores académicos especialistas, o bien les han invitado a ser investigadores visitantes por 3-12 meses, y que sus logros académicos han entrado en la publicación anual de sus resultados académicos.

El que haya un número de obras especiales y libros editados relativamente alto también puede levantar sospechas entre la gente. Según se entiende, sus principales fundamentos son las razones mencionadas anteriormente, aunque también incluyen que la publicación de muchas de estas obras y ensayos se concentra en el año 2018, y que algunas instituciones de estudios latinoamericanos han sido relativamente laxas con la revisión de tales obras, no han sido tan rigurosos como lo son con los investigadores centrados en temas nacionales, así que las obras editadas se han convertido en un formato principal.

\section{Gráfico 1-18. Cantidad de obras y publicaciones académicas por año de las instituciones de estudios latinoamericanos}

Orientando. Temas de Asia Oriental. Sociedad, Cultura y Economía. Revista editada por el Centro de Estudios China-Veracruz de la Universidad Veracruzana, México (Centro de Estudios APEC) / año 10 / número 19/ 


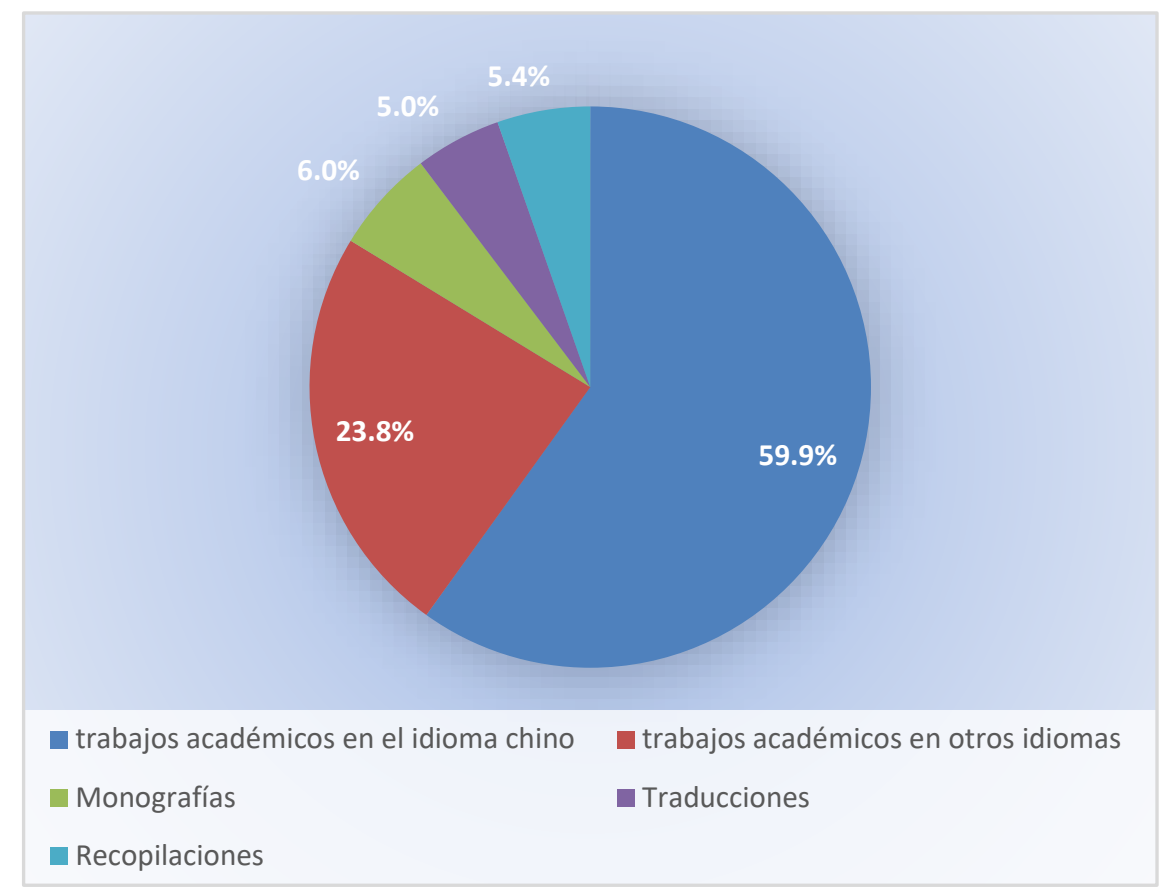

Fuente: Encuesta sobre el desarrollo de instituciones de estudios latinoamericanos en China (1949-2019), Asociación China de Estudios Latinoamericanos, 2019.

Un análisis en detalle de la cantidad media de publicaciones académicas anuales realizadas por las instituciones demuestra que su distribución entre ellas está muy desequilibrada ( ver Gráfico 1-19) . Las estadísticas demuestran que en 2018, hay 13 instituciones que publicaron 10 o más obras académicas en total, un $24 \%$ del total de instituciones entrevistadas; y hay 11 instituciones que en un año han publicado 5 o menos obras académicas, un $21 \%$. Incluso hay siete instituciones que el año pasado no publicaron nada, aunque es comprensible debido a que estas instituciones se crearon apenas en los últimos dos años.

Gráfico 1-19. Tipos de instituciones de estudios latinoamericanos: según su cantidad de publicaciones académicas al año 


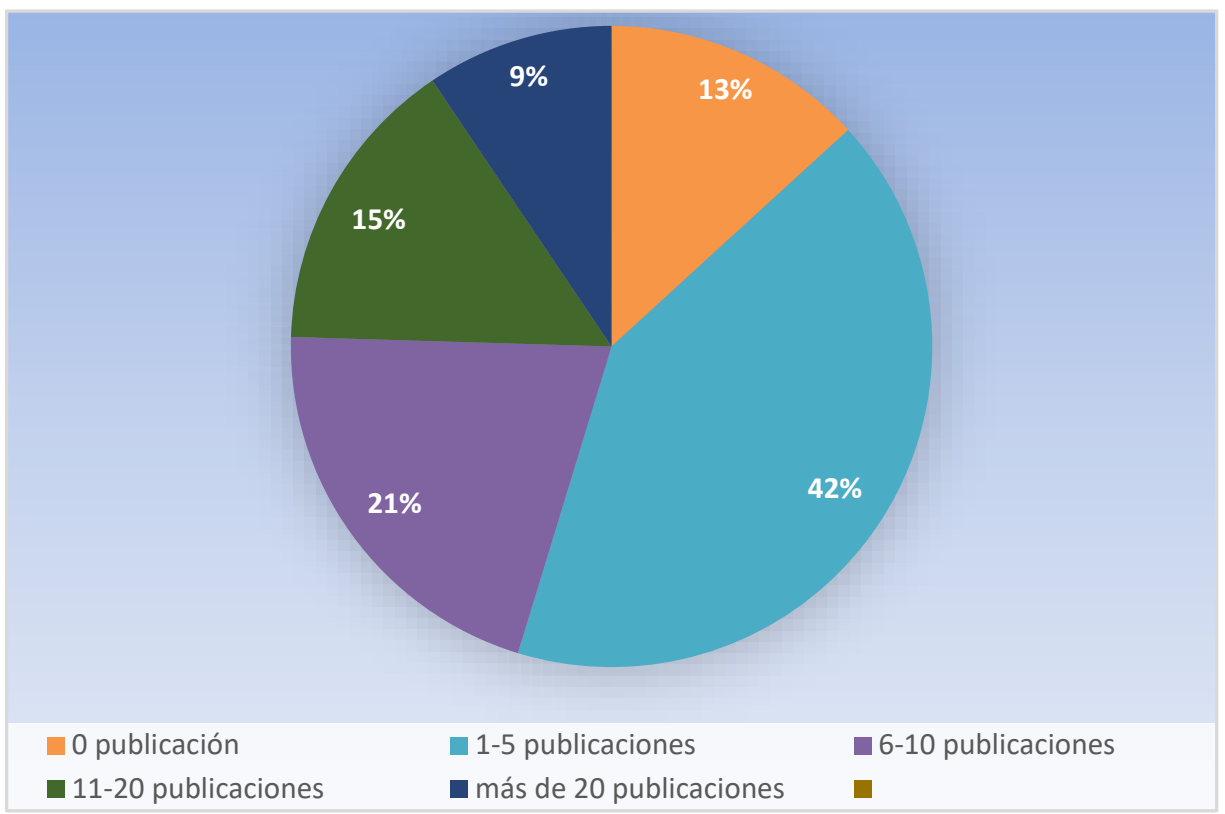

Fuente: Encuesta sobre el desarrollo de instituciones de estudios latinoamericanos en China

(1949-2019), Asociación China de Estudios Latinoamericanos, 2019.

A diferencia de cultivar "los méritos internos" (nei gong), la mayoría de las instituciones de estudios latinoamericanos han sido negligentes a la hora de cultivar los "méritos externos" (wai gong). Es decir, crear una marca institucional de sus obras y creaciones académicas, así como la promoción de sus actividades y logros académicos al exterior. La investigación ha esclarecido que hay 42 instituciones, casi el $80 \%$ de las entrevistadas que no poseen una publicación periódica ( ver Gráfico 1-20 ) .

No obstante, en comparación con una época anterior, actualmente ya hay 11 instituciones que poseen una revista o publicaciones periódicas, lo cual representa un gran avance. La investigación también ha descubierto que cerca de dos tercios de las instituciones no tienen una página web oficial; en esta era de la información, las páginas web sin duda son las tarjetas de presentación internacionales de las instituciones. En comparación con las páginas, las plataformas de redes sociales son más populares. En realidad, son mucho más convenientes según todo punto de vista.

Orientando. Temas de Asia Oriental. Sociedad, Cultura y Economía. Revista editada por el Centro de Estudios China-Veracruz de la Universidad Veracruzana, México (Centro de Estudios APEC) / año 10 / número 19/ 
En teoría, emplear la red social más popular a nivel nacional actualmente -las cuentas públicas de WeChat - debería convertirse en el canal principal de publicación de eventos o para mostrar las publicaciones académicas. Sin embargo, contrario a esta intuición, tan solo 19 instituciones han abierto una cuenta pública de WeChat, un 35,8\% , y más de dos tercios de las instituciones entrevistadas, no poseen una cuenta pública de WeChat. Solo hay 13 instituciones que tienen una cuenta pública de WeChat y también una web oficial, un 24\%; mientras que, al contrario, casi una mitad de ellas ( un 47,2\% ) no tienen "ni lo uno ni lo otro": ni cuenta pública de WeChat, ni página web oficial.

Gráfico 1-20. Creación de marca y promoción de las publicaciones y logros de las instituciones de estudios latinoamericanos

Orientando. Temas de Asia Oriental. Sociedad, Cultura y Economía. Revista editada por el Centro de Estudios China-Veracruz de la Universidad Veracruzana, México (Centro de Estudios APEC) / año 10 / número 19/ 


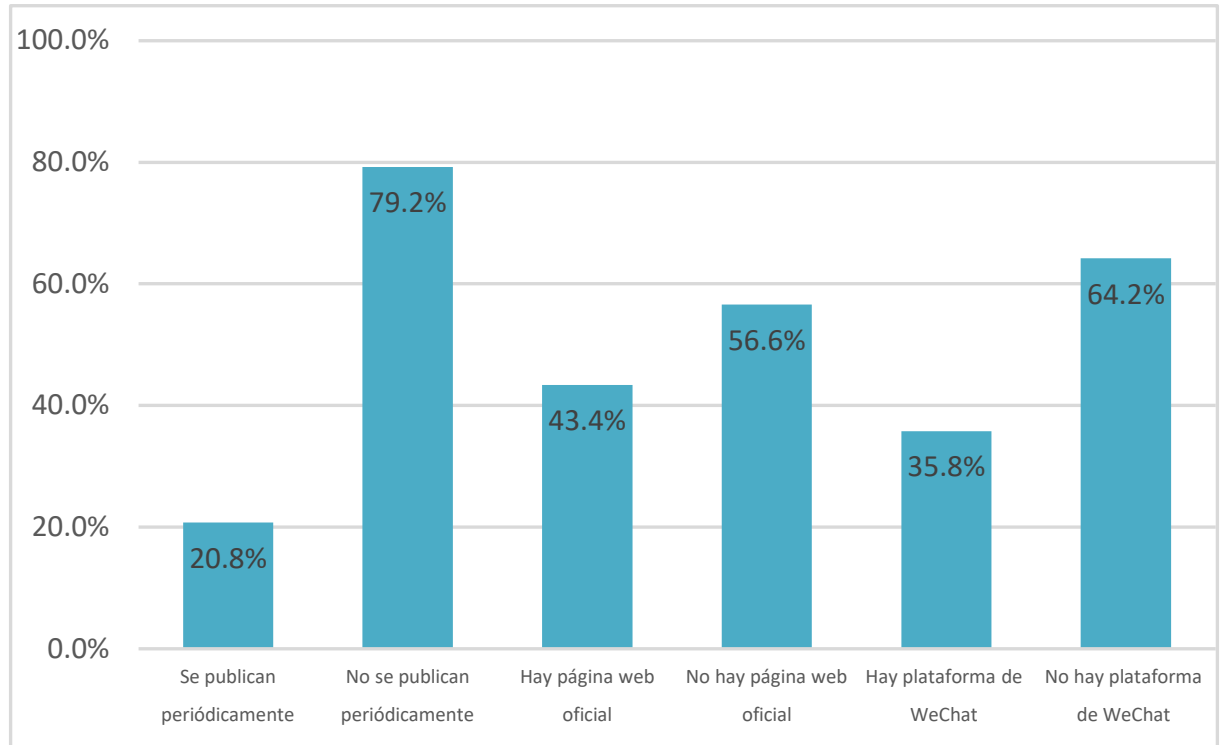

Fuente: Encuesta sobre el desarrollo de instituciones de estudios latinoamericanos en China (1949-2019), Asociación China de Estudios Latinoamericanos, 2019.

( 6 ) Gran desequilibrio en el desarrollo de las disciplinas académicas y en la distribución de los estudios nacionales comparativos

Si bien las instituciones entrevistadas han declarado dedicarse a varios ámbitos de investigación, como la política, la economía, la literatura, la cultura y la historia, todos ellos con relativo interés, incluso algunas de ellas han abordado los temas de la religión y el arte también, aún existe una gran diferencia entre las intenciones de la investigación y los resultados finales en la práctica. Se ha tomado la Revista de Estudios Latinoamericanos ( incluyendo su publicación de anterior nombre Revista de Latinoamérica ) como muestra, para realizar un análisis en profundidad de la distribución de la temática de todos los ensayos académicos publicados desde 1979 hasta hoy ${ }^{(1 .}$

(1) Desde noviembre de 1979 hasta julio de 2019, Revista de Estudios Latinoamericanos (《拉丁美洲研

究》) (, llamada Colección de Estudios Latinoamericanos (Ladingmeizhou Congkan) de 1979 -1985), ha publicado un total de 3.658 artículos. Excluyendo reseñas de conferencias, comunicados de prensa o varias actualizaciones de noticias, un total de 597, los ensayos académicos son un total de 3.061 .

Orientando. Temas de Asia Oriental. Sociedad, Cultura y Economía. Revista editada por el Centro de Estudios China-Veracruz de la Universidad Veracruzana, México (Centro de Estudios APEC) / año 10 / número 19/ 
Como muestra el Gráfico 1-21, según la clasificación legal de materias en China, en Revista de Estudios Latinoamericanos, en torno a un $80 \%$ de los ensayos académicos son sobre economía y política ( incluyendo las relaciones internacionales ) ,de ellos la mayoría son sobre economía, un total de 1.339 artículos, un 43,2\%; los ensayos sobre política ( incluyendo las relaciones internacionales) totalizan 1.123 artículos, un 36,5\% del total; hay 335 ensayos sobre la temática de historia, un 10,9\%. Aparte de estas materias, la cultura, la literatura, el arte, la filosofía, la religión, etc., pese a tener determinada representación, en términos generales, aún hay muy pocos ensayos dedicados a estos ámbitos.

Existe una gran incoherencia entre los objetivos de estos tipos de investigación y los logros reales de tales investigaciones. Esto probablemente se debe a dos razones principales. La primera, que la mayoría de las instituciones dedicadas a los estudios latinoamericanos actuales apenas tiene 5 años, o se han creado especialmente en estos tres últimos años. Así existe cierta obstrucción entre los objetivos propuestos para su investigación y los logros reales. La segunda razón está relacionada con la posición que ostenta la Revista de Estudios Latinoamericanos.

Si bien en la primera mitad de sus publicaciones se habían publicado ensayos y contenidos que tratan sobre: la cultura, religión, filosofía o incluso literatura de Latinoamérica, en las publicaciones posteriores ha pasado de ser una revista principalmente dedicada a las humanidades, la sociedad y cultura (renwen shehui), a ser una revista sobre las ciencias sociales (shehui kexue). Muchas de las instituciones de estudios latinoamericanos nuevas, e incluso algunas de las que se establecieron hace tiempo, con las pautas de conformar un "nuevo modelo de think tank" (xin xing zhiku), están a favor de que su investigación académica atienda de manera directa a las cuestiones reales o temas políticos, económicos o diplomáticos requeridos por las políticas (nacionales).

Orientando. Temas de Asia Oriental. Sociedad, Cultura y Economía. Revista editada por el Centro de Estudios China-Veracruz de la Universidad Veracruzana, México (Centro de Estudios APEC) / año 10 / número 19/ 
Gráfico 1-21. Publicaciones de ensayos académicos en Revista de Estudios Latinoamericanos, según su temática

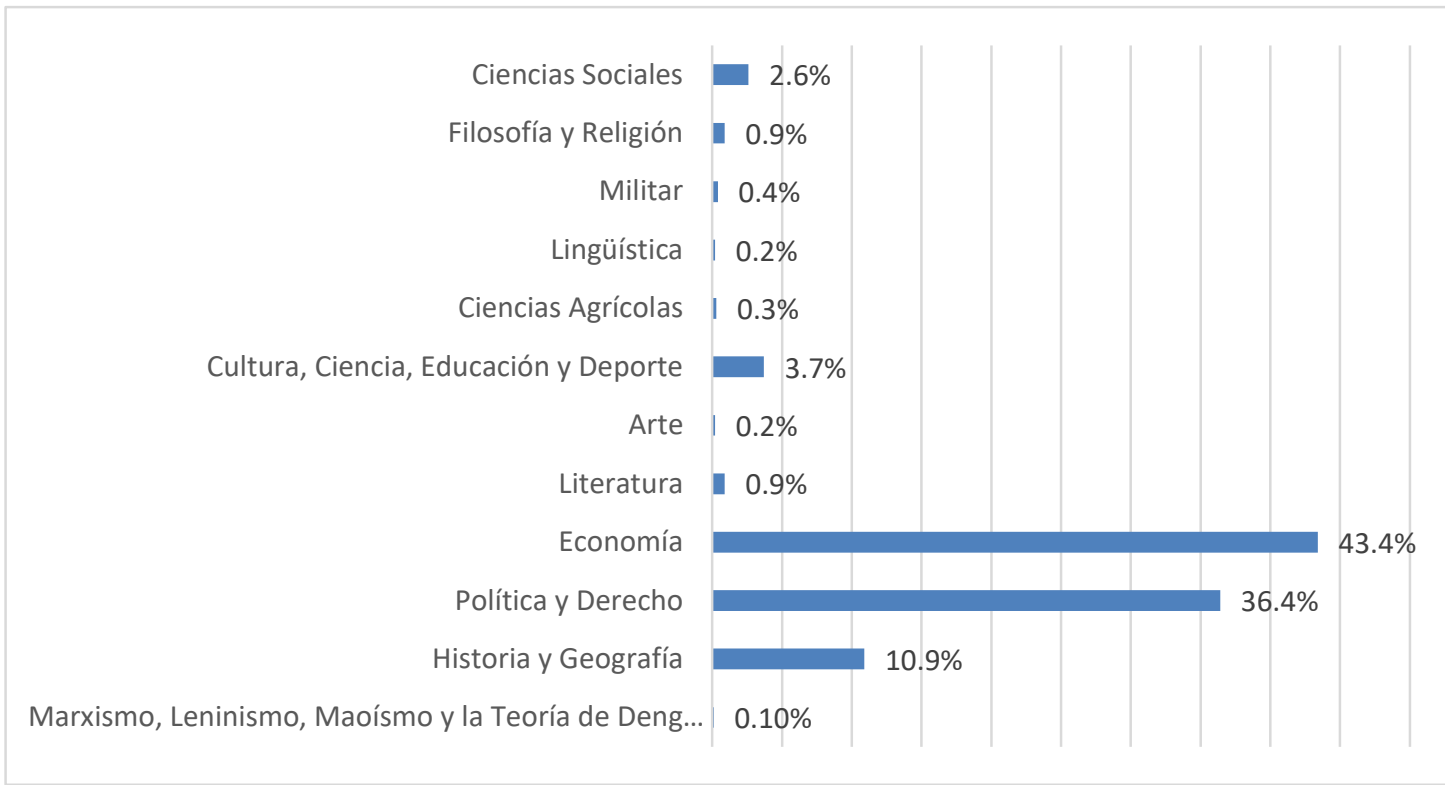

Fuente: Estadísticas organizadas sobre la Revista de Estudios Latinoamericanos (1979-2019) recogidas por el autor de la web china Zhiwang ( www.cnki.net )

Respecto a las regiones y países que se investigan, también existe un desequilibrio claro ( ver Gráfico 1-22 ) . En términos generales, a partir de datos de la Revista de Estudios Latinoamericanos, todos los ensayos y artículos académicos publicados tratan sobre todos los países de Latinoamérica y el Caribe ${ }^{(1)}$, sean países grandes o pequeños, mantengan o no relaciones diplomáticas con China.

En primer lugar, las cuestiones regionales son el principal foco de interés. Del total de todos los artículos académicos publicados por la revista, más de un 55\% ( un total de 1.697 artículos ) versan sobre cuestiones regionales. En segundo lugar, el estudio comparativo entre países principalmente se concentra en tres grandes potencias regionales: Brasil,

(1) El número de artículos sobre países individuales es demasiado pequeño y no es estadísticamente significativo, por lo que no se muestra en el gráfico.

Orientando. Temas de Asia Oriental. Sociedad, Cultura y Economía. Revista editada por el Centro de Estudios China-Veracruz de la Universidad Veracruzana, México (Centro de Estudios APEC) / año 10 / número 19/ 
México y Argentina, que ocupan el 11,1\% (341 artículos), 9,4\% (290 artículos) y 5,1\% (158) del total de los artículos, respectivamente. Por último, algunos países de tamaño intermedio han sido objeto de mayor interés; por ejemplo; Cuba, Chile, Venezuela y Perú.

Los artículos sobre estos países representan en torno al 2,0\%-4,6\%del total de los artículos académicos. Lamentablemente, en los últimos años, algunos países que han estrechado más sus relaciones con China o cuyo estudio representa un mayor valor académico, no han sido lo suficientemente investigados. Por ejemplo, países como Colombia, Ecuador o Panamá, entre otros.

Gráfico 1-22. Artículos académicos publicados por la Revista de Estudios Latinoamericanos, según estudios comparativos y regiones.

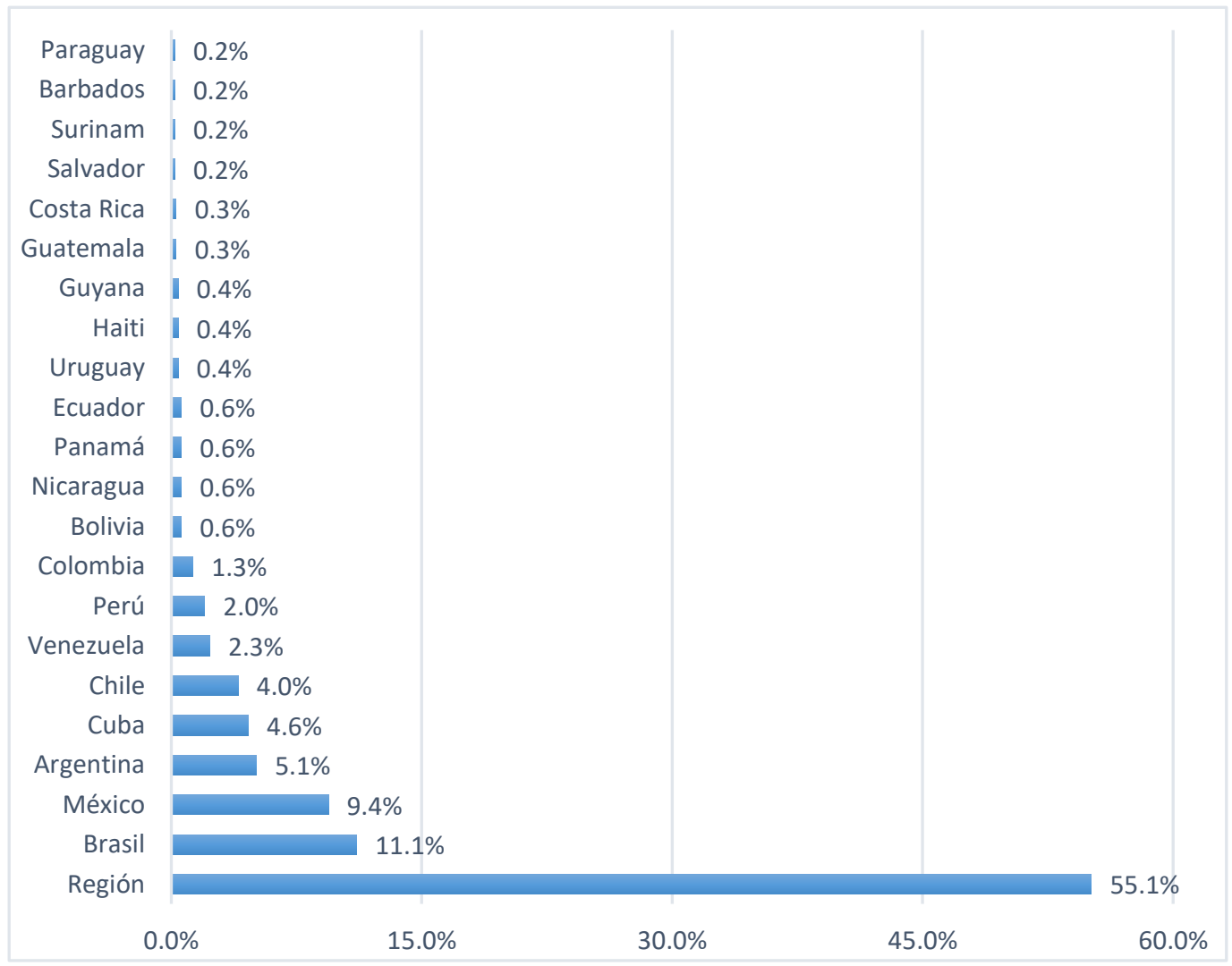

Fuente: Estadísticas organizadas sobre la Revista de Estudios Latinoamericanos (1979-2019) recogidas por el autor de la web china Zhiwang ( www.cnki.net )

\section{Los retos estructurales de los estudios latinoamericanos en China}

Orientando. Temas de Asia Oriental. Sociedad, Cultura y Economía. Revista editada por el Centro de Estudios China-Veracruz de la Universidad Veracruzana, México (Centro de Estudios APEC) / año 10 / número 19/ 
La Encuesta sobre el desarrollo de instituciones de estudios latinoamericanos en China (1949-2019) demuestra que, bajo el impulso doble de la política gubernamental y el rápido desarrollo de las relaciones entre China y Latinoamérica, los estudios latinoamericanos, especialmente en estos últimos cuarenta años, han conseguido un gran progreso con respecto a la infraestructura de software y hardware. A pesar de todo, estos avances no pueden satisfacer las necesidades de la sociedad china con respecto a los estudios latinoamericanos: ya sean estas necesidades de las políticas actuales de China hacia Latinoamérica, de las operaciones de empresas chinas en Latinoamérica, o del público en general para mejorar su conocimiento de la región.

Estas diferencias reflejan cómo, por una parte, la creación de conocimientos sobre Latinoamérica no es suficiente; $y$, por otra parte, debido a la reiterada creación de contenido académico, existe un exceso relativo de información. Por tanto, un desarrollo en profundidad del estudio de Latinoamérica en China presenta un serio reto de transformar su estructura.

\section{( 1 ) Transformar el ámbito de investigación}

Desde hace mucho tiempo, los estudios latinoamericanos en China han seguido dos objetivos principales: uno, la toma de decisión de políticas con respecto a Latinoamérica, y, dos, "servir de referencia" (yizi jingjian). Es decir, aunque lo segundo sirve en parte para crear conocimiento, también posee un fuerte cariz de pragmatismo. Aún más importante, este tipo de pensamiento lineal "proveniente de China y para China" (cong zhongguo lai, dao zhongguo qu) en esencia corre el riesgo de caer en el "etnocentrismo/egocentrismo" (ziwo zhongxin zhuyi), incluso que "algunos puntos de vista y conclusiones sean más bien instintos o anhelos de nuestros académicos, en vez de unos conocimientos obtenidos a través de un conocimiento en profundidad”(『), y así que la investigación académica limite

\footnotetext{
(1) Tang Shipping, Zhang Jie \& Cao Yuyang. (2005). Los estudios regionales en China: logros, brechas y
} expectativas ( 《中国的地区研究: 成就、差距和期待》). En Economía y política mundial (《世界经济与

Orientando. Temas de Asia Oriental. Sociedad, Cultura y Economía. Revista editada por el Centro de Estudios China-Veracruz de la Universidad Veracruzana, México (Centro de Estudios APEC) / año 10 / número 19/ 
su perspectiva en la práctica. También existe una (negativa) tendencia a "problematizar a Latinoamérica" (Lamei wentihua) y de "latinoamericanizar los problemas" (wenti Lameihua).

Actualmente, la situación de los estudios latinoamericanos en China ha cambiado drásticamente, el ámbito de la investigación también debe cambiar rápidamente en respuesta. En primer lugar, con el avance de la globalización, la importancia de Latinoamérica en el orden mundial ha incrementado significativamente. Por consiguiente, también ha despertado un mayor interés por parte de cada vez más investigadores e instituciones académicas. Este tipo de atención no solo se concentra en la región en sí, sino que también cada vez se centra más en las partes beneficiadas.

En segundo lugar, con la reemergencia de China y la continua profundización de relaciones de socios estratégicos entre China y Latinoamérica, China se ha convertido en una parte interesada cada vez más significativa dentro la región latinoamericana. Por tanto, esto ha despertado el interés de las instituciones que estudian a China y Latinoamérica. Es decir, en esta nueva era, el estudio de los asuntos de China y Latinoamérica ha encontrado una intersección en los estudios de las relaciones entre ambas regiones.

A nivel internacional, algunas instituciones dedicadas a la investigación de los asuntos de China, incluso algunas publicaciones académicas internacionales de renombre sobre los asuntos internacionales han publicado alguna edición especial sobre "China y Latinoamérica." No hace falta mencionar que las publicaciones académicas de algunas instituciones con interés en Latinoamérica han tomado "China y Latinoamérica" para publicar ensayos con esta temática principal(1). Este tipo de nuevos cambios exigen a los

\footnotetext{
政治》), volumen 11, p. 12.

(1) Por ejemplo, la revista americana The China Quarterly, que en marzo de 2012 publicó "De la muralla China a la Nueva China continetal : la China y Latinoamérica del siglo XXI"; la revista alemana Journal of Current Chinese Affairs, cuyo primer volumen de 2012 fue "La reacción de Latinoamérica sobre el ascenso de China"; la revista danesa Journal of China and International Relations, que en 2016 publicó la edición especial "Las relaciones internacionales entre China y Latinoamérica en la era revolucionaria del orden mundial"; la revista singapurense Issues \& Studies, cuya primera edición especial en 2017 fue "Análisis
}

Orientando. Temas de Asia Oriental. Sociedad, Cultura y Economía. Revista editada por el Centro de Estudios China-Veracruz de la Universidad Veracruzana, México (Centro de Estudios APEC) / año 10 / número 19/ 
estudios latinoamericanos en China que salgan de "China" y que refuercen e incluyan los intercambios y conversaciones de los investigadores compañeros de los países de la región. Si los estudios latinoamericanos en China solo salen de "China" en términos geográficos y de pensamiento, solo así podrán ofrecer mejor información para la toma de políticas. Asimismo, pueden crear conocimientos para el público, y satisfacer las urgentes necesidades de la sociedad de esta nueva etapa de esta nación con respecto a los estudios latinoamericanos.

Por supuesto, este concepto de "salir de China" (zouchu zhongguo) no es abandonar ni la perspectiva ni la postura de China, sino usar una perspectiva global más amplia para supervisar los estudios latinoamericanos. Se trata de una perspectiva desde el mundo hacia Latinoamérica y, finalmente, hasta China. Bajo este nuevo marco de investigación , Latinoamérica es primero la Latinoamérica del mundo entero, luego es la Latinoamérica de su propia región y finalmente es la Latinoamérica de China.

Con base en esto, el estudio de Latinoamérica en China tiene que asimilar tanto el contenido de China como el proveniente de fuera, especialmente el de Occidente (entre China y América, entre China y Europa, etc.) y con la nueva perspectiva académica de China y Latinoamérica, hay que poner atención en asimilar las lecciones de la investigación y experiencia de otros países sobre Latinoamérica. Asimismo, hay que apoyar la tradición académica de China y la mentalidad independiente e innovadora, establecer facultades académicas de estudios latinoamericanos con características chinas.

político y económico de las relaciones entre China y Latinoamérica y el Journal of Chinese Overseas", cuyo segunda edición especial de 2017 fue "Los inmigrantes chinos en la región de Latinoamérica y el Caribe: historia y situación actual"; la revista estadounidense Journal of Latin American Geography, que cuya segundan edición especial en 2018 fue "Nueva geografía de las relaciones entre China y Latinoamérica" y la revista Americas Quarterly, cuya segunda edición especial en 2019 fue Relaciones entre China y Latinoamérica 2.0; la revista mexicana Journal Competition and Regulation in Network Industries, cuya edición de otoño en 2019 fue El otro extremo de la Ruta de la Seda: las inversiones en infraestructura de China en Latinoamérica; o la revista de Macao Macau Journal of Brazilian Studies, cuya edición especial de 2019 fue La gestión económica de China en Brasil y Latinoamérica: entre cambios de políticas y paradigmas emergentes, etcétera.

Orientando. Temas de Asia Oriental. Sociedad, Cultura y Economía. Revista editada por el Centro de Estudios China-Veracruz de la Universidad Veracruzana, México (Centro de Estudios APEC) / año 10 / número 19/ 


\section{( 2 ) Transformación de la metodología de la investigación}

Con las limitaciones geográficas y de recursos financieros, los estudios latinoamericanos en China nunca han podido realizar una "metodología in situ" durante mucho tiempo ${ }^{(1}$, los métodos de investigación principalmente han dependido del análisis de documentos es cierto que, los documentos informativos siempre ha sido un recurso escaso. En esta nueva era, tras el rápido avance de la globalización y la digitalización, los documentos ya no plantean un problema, sino que el problema es que los métodos de investigación tradicionales ya no pueden adaptarse a los nuevos retos. Debe haber una transformación del método de investigación de observativo a uno participativo.

La esencia de los estudios latinoamericanos es la investigación regional, por lo que son los idiomas y adaptación conceptos clave. A pesar de que la presente investigación apunte a que una parte significativa de los investigadores ya dominan los dos principales idiomas oficiales de Latinoamérica -el español y el portugués- aún casi la mitad de los investigadores solo domina el inglés. En realidad, solo con conocimientos de inglés, no es posible adaptarse a los retos de esta nueva era, incluso no se les pueden considerar unos investigadores académicos de Latinoamérica cualificados.

Esto es aún más patente en la región de Latinoamérica, donde el conocimiento del idioma local y la realización del trabajo in situ son condiciones básicas. Por tanto, es muy importante enfatizar la importancia del dominio del español o el portugués. Se debería considerar el idioma como una habilidad primordial, y alentar a más investigadores de la región a ir y estar presentes allí , a través de una observación de seguimiento y una forma de investigación participativa en primera persona, para obtener experiencias y recursos

\footnotetext{
(1) Yang Hao. (2001). "Habilidades para la investigación de la región del sudeste asiático: una teoría sobre la emancipación metodológica que deberían tener los nuevos estudiantes académicos de relaciones internacionales" (《东南亚区域研究的技艺:新生代国际关系学者应有的方法解放论》), publicado en la revista Foro de investigación de Asia y Pacífico (《亚太研究论坛》(Taiwán), volumen 54, p. 131.
}

Orientando. Temas de Asia Oriental. Sociedad, Cultura y Economía. Revista editada por el Centro de Estudios China-Veracruz de la Universidad Veracruzana, México (Centro de Estudios APEC) / año 10 / número 19/ 
primarios. Sobre esta base, hacer que la investigación de campo junto con el tradicional análisis de documentos se combine y ayuden a reforzar el análisis teórico, para garantizar al mayor grado posible la calidad científica y objetividad de la investigación. Tomando esta vía de investigación no solo se beneficiaría a los investigadores para que éstos conozcan más correctamente la región, sino que también, su materialización aportaría a la sociedad un estudio más real, objetivo y diverso de Latinoamérica.

Sin embargo, el trabajo in situ frecuentemente requiere grandes cantidades de recursos y tiempo, por lo que es muy difícil de generalizar en la práctica. EE. UU. representa el modelo de los estudios latinoamericanos, y pese a que, hasta la fecha se ha basado en la metodología in situ, también ha implementado algunas medidas auxiliares extremadamente importantes. El estudio de Latinoamérica en EE. UU. es "un producto realizado por los norteamericanos y los latinoamericanos conjuntamente, y no para los latinoamericanos. "(1)

A partir de esta experiencia, el autor cree que la investigación in situ es una buena forma de suplementar o de asimilar orgánicamente el estudio de China por los latinoamericanos con el estudio de Latinoamérica por los chinos, y establecer un nuevo modelo académico de relaciones mutuamente beneficiosas de cooperación. Actualmente, con el doble impulso de la emergencia de China y el estrechamiento de relaciones entre China y Latinoamérica, el estudio de China en Latinoamérica también ha comenzado a convertirse en una nueva tendencia, cada vez más popular. Sin embargo, al igual que el estudio de Latinoamérica por parte de China, el estudio de China por parte de Latinoamérica también se enfrenta a similares problemas de la investigación local o in situ.

(1) David L. Szanton (ed.), The Politics of Knowledge: Area Studies and the Disciplines, Oakland: University of California Press p. 24, citado de: Han Qi. (2014). La experiencia de la investigación y enseñanza de los estudios latinoamericanos en las instituciones de educación superior de EE. UU.: un modelo de estudios regionales (《美国高校拉丁美洲研究与教学的经验: 一个区域研究的范例》), publicado en Cuestiones de la enseñanza de la historia (《历史教学问题》), volumen 4, p. 136.

Orientando. Temas de Asia Oriental. Sociedad, Cultura y Economía. Revista editada por el Centro de Estudios China-Veracruz de la Universidad Veracruzana, México (Centro de Estudios APEC) / año 10 / número 19/ 
De cara a los retos comunes y el alto nivel de complementariedad, el estudio recíproco por ambas regiones, completamente puede mediante el intercambio, compartir información y la colaboración se podrá realizar el desarrollo y el avance mutuo: en primer lugar, se podrá promover el desarrollo del estudio de China en Latinoamérica y, en segundo lugar, se podrán potencialmente crear y formar a los socios académicos de China que investigan la región latinoamericana.

\section{( 3 ) Transformación de los contenidos de la investigación}

Dado que la orientación política es la característica general del desarrollo de los estudios latinoamericanos en China, por tanto, es comprensible que, pese a que este campo iniciase sus andaduras por la historia latinoamericana, este ámbito no se haya constituido como el principal ámbito de la investigación sobre Latinoamérica. Incluso no es nada raro que los graduados de másteres y doctorados con una orientación histórica, una vez han obtenido un puesto de trabajo en las instituciones empiecen a concentrarse en la investigación de problemas actuales y reales.

En realidad, la investigación sobre el desarrollo de todas las instituciones nacionales dedicadas a los estudios latinoamericanos ha demostrado lo que ya nos imaginábamos: los estudios de la región se concentran significativamente en la política, la economía y las relaciones internacionales, los tres campos tradicionales de investigación. Estos tres ámbitos frecuentemente han sido concebidos directamente como el "uso pragmático" (youyong zhi yong) para el estrechamiento de las relaciones entre China y Latinoamérica.

Comparado con China, EE. UU., modelo por antonomasia del estudio de Latinoamérica, ofrece un estudio mucho más variado, incluso cada vez más enfocado en el "uso de lo inútil" (wuyong zhi yong). Tomando como ejemplo la publicación oficial de la Asociación Americana de Estudios Latinoamericanos ( LASA, por sus siglas en inglés ), Latin American Research Review , de los 45 artículos académicos publicados en 2017 , un 58\%

Orientando. Temas de Asia Oriental. Sociedad, Cultura y Economía. Revista editada por el Centro de Estudios China-Veracruz de la Universidad Veracruzana, México (Centro de Estudios APEC) / año 10 / número 19/ 
de ellos se centra en las humanidades ( antropología, historia, literatura y cultura ) , un $42 \%$ se centra en las ciencias sociales ( economía, política, asuntos internacionales y sociología ).

De ellos, la investigación literaria y cultural se han convertido en los últimos años en los campos más destacables de la investigación ${ }^{\circledR}$. Y la revista Latin American Research Review, pese se denomina una "revista académica multidisciplinar", al principio publicaba por un tiempo publicaba ensayos académicos sobre la literatura, aunque recientemente se ha centrado más en asuntos reales de economía, política y relaciones internacionales. Por supuesto, quizás sea mejor actualizar los objetivos de la revista y "principalmente (dedicarse a) publicar sobre importantes cuestiones reales y teóricas de la región latinoamericana y las relaciones internacionales entre China y Latinoamérica, los asuntos puntuales importantes e innovar sobre temas de vanguardia y avanzar en resultados científicos". (2)

Precisamente con el impulso acelerador de la orientación política, los estudios latinoamericanos reflejan desequilibrios significativos con respecto al contenido de la investigación. En breve, podría a grandes rasgos resumirse en "diez muchos y diez pocos" (shi duo shi shao): mucho estudio regional, poco estudio comparativo entre países; mucho estudio macro, poco estudio micro; mucho estudio sobre las potencias (de la región), poco estudio sobre los pequeños países (de la región); mucha investigación aplicada, poca investigación básica; mucho estudio sobre los temas calientes, poco estudio sobre temas menos populares; mucha investigación reiterada, poca investigación innovadora; mucho estudio real, poco estudio de la historia; mucho estudio "útil” (youyong), poco estudio

\footnotetext{
(1) Pérez-Liñán, A. (2018). "Report from the Editor (2018)". In Latin American Research Review 53(3), pp. 425-428. DOI: https://doi.org/10.25222/larr.635

(2) Introducción de Revista de Estudios Latinoamericanos ( 《拉丁美洲研究》) , en http://ilas.cass.cn/xsqikan/qkjianjie/[2019-08-11]
}

Orientando. Temas de Asia Oriental. Sociedad, Cultura y Economía. Revista editada por el Centro de Estudios China-Veracruz de la Universidad Veracruzana, México (Centro de Estudios APEC) / año 10 / número 19/ 
“inútil” (wuyong); mucha investigación fragmentada, poca investigación sistemática; y, mucho estudio de una disciplina, poco estudio multidisciplinar.

En realidad, el fundamento de estos "muchos" y "pocos" refleja el fuerte pragmatismo que tinta y obstruye la investigación académica de Latinoamérica, la excesiva importancia dada a la investigación aplicada y la omisión de la investigación básica académica. Sin embargo, hay que alertar de que ha sido confirmado que no hay suficiente robustez académica en el apoyo de conocimientos básicos, por lo que no se pueden ofrecer recomendaciones de alto valor para las políticas. En otras palabras, “entre dar importancia al significado de la academia y ofrecer bunas recomendaciones para las políticas gubernamentales, en sí no debería ser contradictorio, sino que debería ayudar a avanzar ambas de manera recíproca". (1)

En esta nueva etapa, tras la expansión del equipo dedicado a los estudios latinoamericanos y, en especial, con la mayor diversidad en la formación de los nuevos estudiantes investigadores, el contenido de los estudios latinoamericanos inevitablemente deberá tender hacia una mayor diversidad en el futuro. Sin embargo, esta mayor diversidad en el contenido, por un lado, dependerá de la autonomía de las instituciones y los investigadores; y, por otra parte, dependerá de la orientación positiva de las publicaciones académicas (como Latin American Research Review y las asociaciones académicas (como la Asociación China de Estudios Latinoamericanos).

\section{Los estudios latinoamericanos en China en esta nueva etapa}

\footnotetext{
(1) Tang Shipping, Zhang Jie, Cao Yuyang. (2005). Los estudios regionales en China: logros, brechas y expectativas ( 《中国的地区研究:成就、差距和期待》), publicado en Economía y política mundial (《世 界经济与政治》), volumen 11, p. 14.

Orientando. Temas de Asia Oriental. Sociedad, Cultura y Economía. Revista editada por el Centro de Estudios China-Veracruz de la Universidad Veracruzana, México (Centro de Estudios APEC) / año 10 / número 19/ 
Tras 70 años, especialmente en estos últimos cuarenta años de desarrollo, los estudios latinoamericanos en China han establecido un nuevo escenario y han avanzado hasta un nuevo momento histórico: frente a una nueva etapa, hay que servir la nueva etapa. "La entrada de China a esta nueva época ,donde cada día se aproxima más a ser un actor central , señaliza el actual estado del desarrollo de China, su tendencia y su visión de desarrollo, que comparte la misma dirección con el resto del mundo, entrelazándose mutuamente y lleno de emoción recíproca, China está cambiando profundamente al mundo y el mundo está influyendo profundamente a China."(1)

En este nuevo inicio histórico, la demanda por el estudio de Latinoamérica en China va a ser mayor, va a tener requisitos más altos, fuertes y va a apuntar al futuro. De cara a este nuevo momento histórico, las instituciones de estudios latinoamericanos en China y sus académicos deberán urgentemente transformar su concepción y forma de pensamiento, por una perspectiva del mundo, una metodología de investigación más científica, unos sujetos de investigación más diversos, fortalecer significativamente la investigación básica. Es decir, tener un plan de formación académica "robusto" (hou ji), también se deberá emplear la investigación "capilar" (bo fa) para las políticas.

Sin embargo, debemos tener claro que estos cambios estructurales tan necesitados, absolutamente no son labor de un día. Pese al desarrollo fragmentado e intermitente de los primeros 50 años y el desarrollo a increíble velocidad de los 20 años posteriores, los estudios latinoamericanos en la actualidad aún se ubican en una fase inicial, y en el futuro por un tiempo significativo seguirán en esta fase, imposible de eliminar un servicio de alta precisión para las políticas estratégicas del Estado en Latinoamérica aún requerirá tiempo.

La creación de conocimientos tiene un camino largo y lleno de obstáculos. Y para pasar de esta fase inicial, es probable que harán falta por lo menos dos o tres generaciones más

(1) Tong Xin. (2019). Sobre la nueva era (《论新时代》), publicado en Qiu shi (《求是》), http://www.qstheory.cn/dukan/qs/2019-01/01/c_1123923778.htm

Orientando. Temas de Asia Oriental. Sociedad, Cultura y Economía. Revista editada por el Centro de Estudios China-Veracruz de la Universidad Veracruzana, México (Centro de Estudios APEC) / año 10 / número 19/ 
trabajo activo y transformación proactiva. Tomando hoy como ejemplo, encarando los retos, la Asociación China de Estudios Latinoamericanos aún debe transformarse, y convertirse en el líder de esta gran transformación. Debe constituir la asociación de investigadores de Latinoamérica integral más grande a nivel nacional, y de cara al desarrollo institucional “explosivo", la Asociación China de Estudios Latinoamericanos tal vez esté confundida: contenta por el "desarrollo floreciente", pero preocupada por este "crecimiento salvaje".

De cara a la Asociación China de Estudios Latinoamericanos de esta nueva era, en el futuro probablemente será no solo necesario cambiar o ampliar su objetivo de una función de cuerpo "colectivo" a una "servicial” y "de liderazgo", y deberá esforzarse por asistir a cada vez más nuevas instituciones emergentes a sobrepasar "los tres pasos históricos" , ayudándoles a convertir su fuerza en números en la fuerza de un auténtico ejército. Este sería el primer paso, además de un paso importante, para dejar atrás la fase inicial actual y situarse en este nuevo inicio histórico para avanzar hacia el futuro.

Orientando. Temas de Asia Oriental. Sociedad, Cultura y Economía. Revista editada por el Centro de Estudios China-Veracruz de la Universidad Veracruzana, México (Centro de Estudios APEC) / año 10 / número 19/ 